\title{
Neutral production of hydrogen isocyanide (HNC) and hydrogen cyanide (HCN) in Titan's upper atmosphere
}

\author{
E. Hébrard ${ }^{1,2}$, M. Dobrijevic ${ }^{1,2}$, J. C. Loison $^{3}$, A. Bergeat ${ }^{3}$, and K. M. Hickson ${ }^{3}$ \\ 1 Univ. Bordeaux, LAB, UMR 5804, 33270 Floirac, France \\ e-mail: hebrard@obs .u-bordeaux1.fr \\ 2 CNRS, LAB, UMR 5804, 33270 Floirac, France \\ 3 Institut des Sciences Moléculaires, UMR 5255, CNRS-Université de Bordeaux, 351 cours de la Libération, 33405 Talence Cedex, \\ France
}

Received 18 January 2012 / Accepted 11 March 2012

\begin{abstract}
Aims. Following the first detection of hydrogen isocyanide (HNC) in Titan's atmosphere, we have devised a new neutral chemical scheme for hydrogen cyanide (HCN) and $\mathrm{HNC}$ in the upper atmosphere of Titan.

Methods. Our updated chemical scheme contains 137 compounds (with $\mathrm{C}, \mathrm{H}, \mathrm{O}$ and $\mathrm{N}$ elements) and 788 reactions (including 91 photolysis processes). To improve the chemistry of $\mathrm{HNC}$ and $\mathrm{HCN}$, a careful review of the literature has been performed to retrieve critical reaction rates and to evaluate their uncertainty factors. We have also estimated the reaction rates of 48 new reactions using simple capture theory.

Results. Our photochemical model gives abundances of $\mathrm{HNC}$ and $\mathrm{HCN}$ in reasonable agreement with observations. An uncertainty propagation study shows large uncertainties for HNC and relatively moderate uncertainties for HCN. A global sensitivity analysis pinpoints some key reactions to study as a priority to improve the predictivity of the model.

Conclusions. In particular, our knowledge of the isomerization of $\mathrm{HNC}$ via the reaction $\mathrm{H}+\mathrm{HNC} \rightarrow \mathrm{HCN}+\mathrm{H}$ and the chemistry of $\mathrm{H}_{2} \mathrm{CN}$ needs to be improved. This study of the neutral chemistry taking place in the upper atmosphere of Titan is a prerequisite for future ionospheric models since ion-neutral reactions may also contribute significantly to HNC and HCN production.
\end{abstract}

Key words. planets and satellites: individual: Titan - planets and satellites: atmospheres - planets and satellites: composition astrochemistry

\section{Introduction}

Based on the fact that $\mathrm{HCNH}^{+}$was considered as an important ionospheric species in Titan's atmosphere (Banaszkiewicz et al. 2000), Petrie (2001) made the hypothesis that hydrogen isocyanide (HNC) could be formed by the dissociative recombination of $\mathrm{HCNH}^{+}$in Titan's upper atmosphere where it might be detectable and might also play a part in the formation of more complex nitriles found on Titan. Recently, observations of Titan performed with the HIFI heterodyne submillimeter instrument aboard the Herschel Space Observatory (as part of the guaranteed time key program "Water and related chemistry in the solar system" (HssO), Hartogh et al. 2009), allowed the first detection of HNC in Titan's atmosphere through the measurement of its emission line from the $J=6 \rightarrow 5$ rotational transition at $543.897 \mathrm{GHz}$ (Moreno et al. 2010). Their preliminary analysis suggests that the bulk of this emission must originate at altitudes above $300 \mathrm{~km}$. However, the observations cannot strictly establish a HNC vertical profile (Moreno et al. 2011). Petrie (2001) argued that HNC was likely to be formed almost entirely by an ion-molecule mechanism and that neutral formation pathways were not viable. As a consequence, Petrie (2001) suggested that the concentration profile for $\mathrm{HNC}$ as a function of altitude would follow the typical profile for a polyatomic ion rather than a neutral molecule. So, according to Petrie (2001), HNC might be located mainly in the ionosphere with a peak of abundance around $1200 \mathrm{~km}$.
Since the neutral composition of the atmosphere is a prerequisite for ionospheric models, it is of prime importance to study carefully the production of neutral species production in addition to loss processes for $\mathrm{HNC}$ and $\mathrm{HCN}$, since $\mathrm{HCN}$ is strongly related to HNC. Since HNC was not considered in previous photochemical models, it is necessary to build a new chemical scheme devoted to HNC chemistry and its putative interactions with other species. The chemistry of nitrogen compounds at low temperatures (between 100 and $200 \mathrm{~K}$ ), either in cold planetary atmospheres or in protoplanetary disks, is not well known (Hébrard et al. 2006; Vasyunin et al. 2008; Hébrard et al. 2009). Therefore, it is also critical to evaluate the uncertainties attached to the reviewed reaction rates.

In the present paper, we investigate the production of $\mathrm{HNC}$ via neutral reactions. A careful investigation of neutral production and loss processes for both $\mathrm{HNC}$ and $\mathrm{HCN}$ has been carried out. A 1D photochemical model is used to infer the abundance of HNC as a function of altitude. Our study includes an uncertainty propagation study and a sensitivity analysis to determine the key reactions of our chemical scheme. We briefly present our photochemical model in Sect. 2. The methodology we have adopted to build the chemical scheme for $\mathrm{HNC}$ and $\mathrm{HCN}$ is presented in detail in Sect. 3. In Sect. 4, we compare the computed abundance profiles of $\mathrm{HNC}$ and $\mathrm{HCN}$ with the available observations. We present the main reactions for the neutral production and loss of these compounds in the current model. A local sensitivity study is carried out in Sect. 5 to highlight the importance 
of the HNC isomerization reaction. An uncertainty propagation study is presented in Sect. 6 and a global sensitivity analysis is performed subsequently in Sect. 7 to determine the key reactions which are important to study in priority to improve the predictivity of our model. The main conclusions of our work are summarized in Sect. 8. Some selected reactions (reactions that are important for the production of $\mathrm{HNC}$ or $\mathrm{HCN}$ and reactions that contribute significantly to the uncertainties on their abundances) are commented in Sect. A.

\section{Photochemical model}

The photochemical model is derived from the Hébrard et al. (2007) model with a modification of the numerical solver presented in Dobrijevic et al. (2010a). Instead of using a classical Crank-Nicholson method, we now use the ODEPACK library, which implements Hindmarsh's solvers for ordinary differential equations (Hindmarsh 1983). Our photochemical 1D model uses a constant background atmosphere with constant boundary conditions. Atmospheric parameter inputs $(T, P, n)$ were taken from Yelle et al. (1997) recommended engineering model. We use a non-uniform grid of altitude with 125 levels from the ground to $1300 \mathrm{~km}$. Two consecutive levels are separated by a distance smaller than $H(z) / 5$, where $H(z)$ is the atmospheric scale height at altitude $z$. A zero flux was assumed as an upper boundary condition for most of the species, except for atomic hydrogen $\mathrm{H}$ and molecular hydrogen $\mathrm{H}_{2}$, which were allowed to escape with velocities following Jean's thermal escape mechanism, and for water $\mathrm{H}_{2} \mathrm{O}$, which exhibits an external influx equal to $5 \times 10^{6} \mathrm{~cm}^{-2} \mathrm{~s}^{-1}$ to account for the water influx arising from micrometeorites initiating oxygen chemistry in Titan's atmosphere (Feuchtgruber et al. 1997). At the lower boundary, methane $\mathrm{CH}_{4}$ abundances was set to its tropopause abundance $1.41 \times 10^{-2}$. The abundance of carbon monoxide $\mathrm{CO}$ at the surface was assumed to be $5.2 \times 10^{-5}$ on the basis of the (Gurwell \& Muhleman 2000) high resolution ground-based interferometric observations. Molecular hydrogen $\mathrm{H}_{2}$ abundance was assumed to be equal to $1.1 \times 10^{-3}$ following (Samuelson et al. 1997). Calculations are performed with a solar zenith angle of $50^{\circ}$ to account for diurnally averaged conditions at the equator. The eddy diffusion coefficient $K(z)$ is a free parameter of $1 \mathrm{D}$ photochemical models which is not well constrained. We use the value derived by Hörst et al. (2008) as a mean profile among all the different profiles that have been published so far (see Fig. 1).

\section{Chemical scheme}

The basis of the chemical scheme is presented in Hébrard et al. (2006) and Hébrard et al. (2009). In the present work, many rate constants have been updated and numerous reactions have been added. Our new chemical scheme includes 137 compounds and 788 reactions (91 photodissocation processes, 2 dissociation processes of $\mathrm{N}_{2}$ by cosmic rays, 694 bimolecular reactions and 94 termolecular reactions). The complete list of the reactions is available upon request or can be downloaded from the KInetic Database for Astrochemsity (KIDA, http://kida. obs.u-bordeaux 1.fr). In the present paper, we only present reactions which are essential for the study of $\mathrm{HCN}$ and $\mathrm{HNC}$, either because they are important for their neutral production and/or loss or because they contribute significantly to the uncertainties on their abundances.

The methodology we have adopted to build a chemical scheme for HNC and HNC is the following. As a first step, all

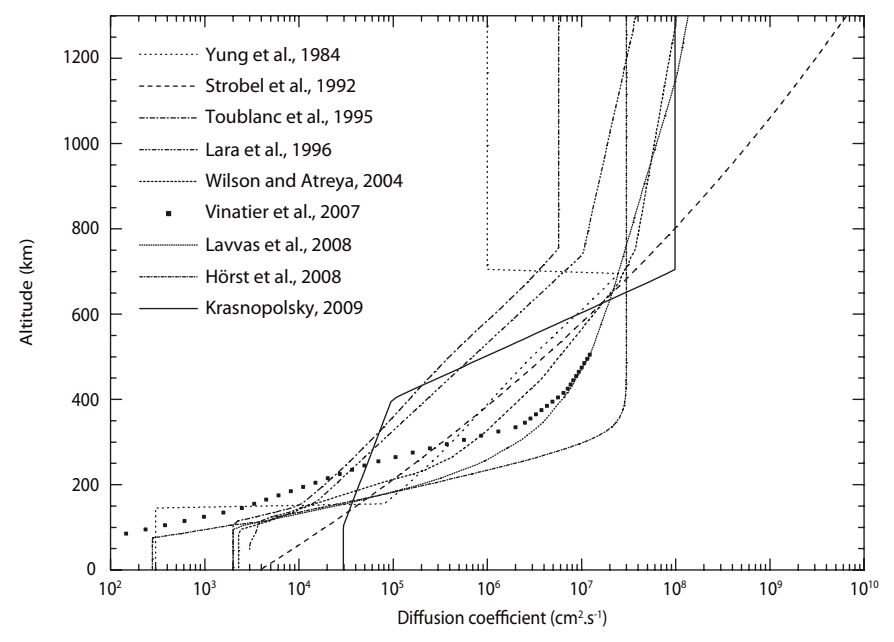

Fig. 1. Eddy diffusion profiles from various photochemical models (Yung et al. 1984; Strobel et al. 1992; Toublanc et al. 1995; Lara et al. 1996; Wilson \& Atreya 2004; Vinatier et al. 2007; Lavvas et al. 2008; Hörst et al. 2008; Krasnopolsky 2009).

the reactions related to $\mathrm{HCN}$ found in the chemical schemes published by Hébrard et al. (2006) and other photochemical models were checked and updated, by including in addition new reactions found in the literature. For all these reactions, we investigated their efficiency to produce HNC. In a second step, we completed the HNC scheme by introducing all neutral reactions producing of destroying HNC that we could find in the literature. Then, based on the relative abundance of the various chemical species computed by our photochemical model, we estimated what reactions currently missing in our chemical scheme might be important by systematically evaluating the cross-reactions involving $\mathrm{HCN}$ or HNC between the main species of Titan's atmosphere: C, H, N $\left({ }^{4} \mathrm{~S}\right), \mathrm{N}\left({ }^{2} \mathrm{D}\right), \mathrm{CH}, \mathrm{CH}_{3}, \mathrm{CH}_{4}, \mathrm{C}_{2} \mathrm{H}_{2}, \mathrm{C}_{2} \mathrm{H}_{4}, \mathrm{NH}$, $\mathrm{CN}, \mathrm{CH}_{2} \mathrm{NH}, \mathrm{H}_{2} \mathrm{CN}$, etc. Finally, we also estimated what reactions might be relevant to improve the chemical scheme, in particular to avoid the artificial formation of important sink species (species which are efficiently produced but not destroyed in the model). At the end, the chemical scheme consists of 56 reactions with $\mathrm{HCN}$ and 22 reactions with HNC (including photolysis processes). Among these reactions, we have estimated in the present work the rate constants of 12 reactions for $\mathrm{HCN}$ and of 14 reactions for HNC. This illustrates the lack of information regarding $\mathrm{HNC}$ reactivity in the literature.

\subsection{Estimation of reaction rates for new processes}

When introducing reactions with unknown reaction rates (without experimental measurements and/or theoretical calculations to rely upon) in the temperature range of interest ( $T \in$ [100-200] K), one major concern is to make a reasonble estimation of their reaction rates. In the following, we explain how we have estimated the rate constants and branching ratios for various reactions. For the evaluation of chemical rate constants between $150 \mathrm{~K}$ and $200 \mathrm{~K}$ the presence of an energetic barrier is critical. When no information was available, the presence and the values of any energetic barriers to the entrance valley for the important reactions (in terms of production and/or loss rate) were calculated at the M06-2X/cc-pVTZ level using the Gaussian09 software package (Frisch et al. 2009) except for the $\mathrm{H}+\mathrm{H}_{2} \mathrm{CN}, \mathrm{N}\left({ }^{4} \mathrm{~S}\right)+\mathrm{H}_{2} \mathrm{CN}$ and $\mathrm{N}\left({ }^{2} \mathrm{D}\right)+\mathrm{HCN}$ reactions for which calculations were performed also at MRCI+Q/vqz level 
E. Hébrard et al.: Neutral production of HNC and HCN in Titan's upper atmosphere

Table 1. New photodissociation processes included in the model (update of Hébrard et al. 2009).

\begin{tabular}{|c|c|c|}
\hline $\begin{array}{l}\text { Reaction } \\
\text { number }\end{array}$ & Quantum yield & References \\
\hline $\mathrm{CH}_{2} \mathrm{NH}+\mathrm{h} v \rightarrow \mathrm{HCN}+\mathrm{H}+\mathrm{H}$ & $q=0.3, \lambda \in[200,250] \mathrm{nm}$ & Bruna et al. (1985), \\
\hline $\mathrm{CH}_{2} \mathrm{NH}+\mathrm{h} v \rightarrow \mathrm{H}_{2} \mathrm{CN}+\mathrm{H}$ & $\begin{array}{l}q=0.7, \lambda \in[200,250] \mathrm{nm} \\
q=1.0, \lambda \in[251,320] \mathrm{nm}\end{array}$ & $\begin{array}{l}\text { Sumathi (1996), } \\
\text { Chestnut (2001) }\end{array}$ \\
\hline $\mathrm{CH}_{2} \mathrm{NH}+\mathrm{h} v \rightarrow \mathrm{HCN}+\mathrm{H}_{2}$ & $q=0.3, \lambda \in[321,328] \mathrm{nm}$ & \\
\hline $\mathrm{CH}_{2} \mathrm{NH}+\mathrm{h} v \rightarrow \mathrm{HNC}+\mathrm{H}_{2}$ & $q=0.7, \lambda \in[321,328] \mathrm{nm}$ & \\
\hline $\mathrm{N}_{2} \mathrm{H}_{4}+\mathrm{h} v \rightarrow \mathrm{N}_{2} \mathrm{H}_{3}+\mathrm{H}$ & $q=1.0$ & Vaghjiani (1993) \\
\hline $\mathrm{CH}_{3} \mathrm{NH}_{2}+\mathrm{h} v \rightarrow \mathrm{CH}_{2} \mathrm{NH}+\mathrm{H}+\mathrm{H}$ & $\begin{array}{c}q=1.0, \lambda \in[139,164] \mathrm{nm} \\
q=0.55, \lambda \in[165,247] \mathrm{nm}\end{array}$ & Hubin-Franskin et al. (2002) \\
\hline $\mathrm{CH}_{3} \mathrm{NH}_{2}+\mathrm{h} v \rightarrow \mathrm{HCN}+\mathrm{H}_{2}+\mathrm{H}+\mathrm{H}$ & $q=0.198, \lambda \in[165,247] \mathrm{nm}$ & \\
\hline $\mathrm{CH}_{3} \mathrm{NH}_{2}+\mathrm{h} v \rightarrow \mathrm{CN}+\mathrm{H}_{2}+\mathrm{H}_{2}+\mathrm{H}$ & $q=0.252, \lambda \in[165,247] \mathrm{nm}$ & \\
\hline $\mathrm{C}_{2} \mathrm{H}_{3} \mathrm{CN}+\mathrm{h} v \rightarrow \mathrm{C}_{2} \mathrm{H}_{2}+\mathrm{HCN}$ & $q=0.15$ & Eden et al. (2003), \\
\hline $\mathrm{C}_{2} \mathrm{H}_{3} \mathrm{CN}+\mathrm{h} v \rightarrow \mathrm{HC}_{3} \mathrm{~N}+\mathrm{H}_{2}$ & $q=0.59$ & Lavvas et al. (2008) \\
\hline $\mathrm{C}_{2} \mathrm{H}_{3} \mathrm{CN}+\mathrm{h} v \rightarrow \mathrm{C}_{2} \mathrm{H}_{3}+\mathrm{CN}$ & $q=0.01$ & \\
\hline $\mathrm{H}_{2} \mathrm{CN}+\mathrm{h} v \rightarrow \mathrm{HCN}+\mathrm{H}$ & $q=1.0, \lambda \in[280,288] \mathrm{nm}$ & $\begin{array}{c}\text { Nizamov \& Dagdigian (2003) } \\
\text { Teslja et al. (2006) }\end{array}$ \\
\hline
\end{tabular}

using the Molpro software package (Werner et al. 2010). For the other reactions, identified as being less important, the presence or the absence of a barrier was deduced from general considerations. When a reaction was thought to proceed through direct abstraction, its rate constant has been estimated by comparison with known similar reactions. When a reaction was thought to proceed through addition (as is the case with most of the radical-radical reactions), in the absence of theoretical calculations, we have considered that there was no barrier when the ground state of the adduct arises from pairing up electrons on the two radicals reactants, whereas the surface was likely be repulsive if all the electrons remain unpaired. Therefore, doublet + doublet reactions were considered to have no barrier for the singlet surface but a barrier for the triplet surfaces (which is in good agreement with experimental and theoretical results for $\mathrm{H}+$ alkyl or alkyl + alkyl reactions for example, Harding et al. 2005; Klippenstein et al. 2006).

When no energetic barrier was found to be present, the value of the rate constant was estimated using long-range forces, mainly through dispersion interactions (Stoecklin \& Clary 1992; Georgievskii \& Klippenstein 2005), and by taking into account the electronic degeneracy $\gamma_{\mathrm{el}}$. The electronic degeneracy factors were calculated by applying the spin and orbital correlation rules to the potential energy surfaces that correlate the separated reactants with the separated products. Using a capture rate, $k_{\text {capture }}$, generally overestimates the rate constant by a uncertainty factor $F_{\text {capture }}=3$ at most (Georgievskii \& Klippenstein 2005) except for specific mechanisms for which the potential coexistence of a van der Waals complex and a submerged barrier could play an important role and lead to low rate constant values at $300 \mathrm{~K}$ (like for $\mathrm{OH}+$ alkenes or $\mathrm{CN}+$ alkenes reactions). Accordingly, the nominal rate constant used in the model for such reactions is $k=\gamma_{\mathrm{el}} \times k_{\text {capture }} / \sqrt{F_{\text {capture }}}$ to which is associated an uncertainty factor $F=\sqrt{F_{\text {capture }}}$. As a result, the minimum and maximum values expected for this effective rate constant are $k_{\min }=\gamma_{\mathrm{el}} \times$ $k_{\text {capture }} / F_{\text {capture }}$ and $k_{\max }=\gamma_{\mathrm{el}} \times k_{\text {capture }}$, respectively. Values for the effective uncertainty factor $F$ were estimated mainly by comparison with similar reactions and also by taking into account the uncertainties on electronic degeneracy when no ab-initio calculations were available. Branching ratios were estimated from ab-initio calculations except for the key $\mathrm{H}+\mathrm{H}_{2} \mathrm{CN}$ reaction for which we performed statistical calculations of the microcanonical rate constants of the various steps of the mechanism (Bergeat et al. 2009).

\subsection{Photolysis processes}

In our model we consider that the photolysis of HNC is similar to the photolysis of $\mathrm{HCN}$ (using the identical absorption cross sections, dissociative thresholds and quantum yields). Compared to the Hébrard et al. (2009) model, we add several photolysis processes which are presented in Table 1.

\section{Photochemical model results}

\subsection{Comparison with observations}

\subsubsection{HNC observations}

Very recently, Moreno et al. (2011) reported the first identification of HNC in Titan's atmosphere from observations using the HIFI instrument on the Herschel ${ }^{1}$ Space Observatory. The column density of HNC inferred from these observations is in the range $(0.6-1.5) \times 10^{13} \mathrm{~cm}^{-2}$ for altitudes between 400 and $1000 \mathrm{~km}$, but the authors noticed that it was not possible to constrain the vertical profile of HNC from these data. Several constant profiles of HNC give a satisfactory agreement with the observations depending on the mixing ratio and the altitude cutoff. These profiles are presented in Fig. 2 and are compared with our model. The column density we obtain is $3.4 \times 10^{13} \mathrm{~cm}^{-2}$ above $500 \mathrm{~km}$ whereas the value derived by Moreno et al. (2011) at this altitude is $1.2 \times 10^{13} \mathrm{~cm}^{-2}$ (about 3 times lower). We will see in the following that this discrepancy can be simply explained by our poor knowledge of some key reactions.

\subsubsection{HCN observations}

The neutral composition of Titan's upper atmosphere between 1000 and $1100 \mathrm{~km}$ has been inferred from the interpretation of Cassini Ion and Neutral Mass Spectrometer (INMS) measurements by Magee et al. (2009). In particular, the global average mixing ratio of $\mathrm{HCN}$ at $1050 \mathrm{~km}$ is $(2.44 \pm 0.10) \times 10^{-4}$. Previous interpretation of INMS data from Vuitton et al. (2007) gave a similar abundance of HCN of $2.0 \times 10^{-4}$ at $1100 \mathrm{~km}$, with an uncertainty factor of 2-3. Geballe et al. (2003) detected $\mathrm{HCN}$ emission features in a high resolution spectrum near $3 \mu \mathrm{m}$

${ }^{1}$ Herschel is an ESA space observatory with science instruments provided by European-led Principal Investigator consortia and with important participation from NASA. 


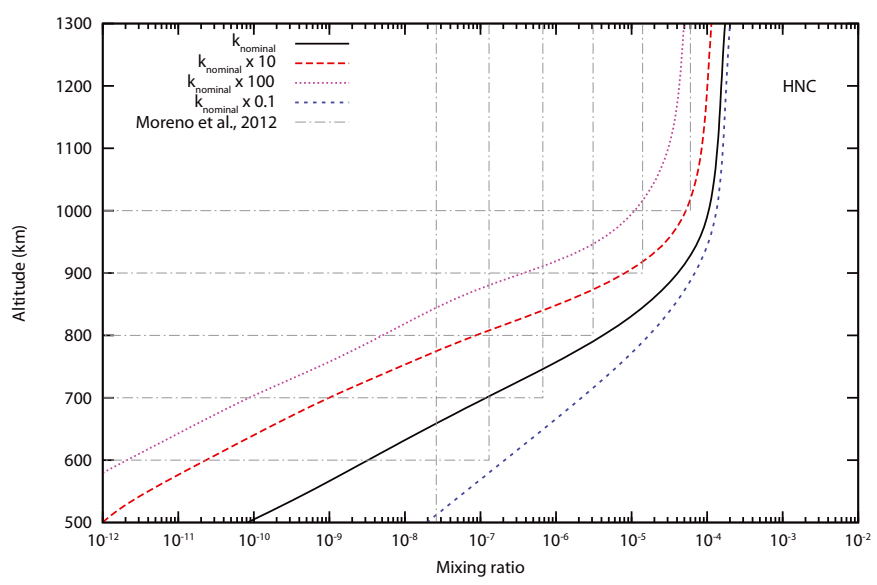

Fig. 2. Mixing ratio of HNC in the upper atmosphere of Titan. Nominal model (solid line) and the different acceptable profiles derived from recent Herschel observations (Moreno et al. 2011) (grey dotted lines). Local sensitivity analysis for the isomerization reaction $\mathrm{H}+\mathrm{HNC} \rightarrow$ $\mathrm{HCN}+\mathrm{H}$ is also illustrated by changing its rate by a factor of 10 or 100 .

acquired at the Keck II telescope. These data were re-analyzed by Yelle \& Griffith (2003) with a model for fluorescence of sunlight in the $v 3$ band of $\mathrm{HCN}$ and by Kim et al. (2005) with an updated model. Their results were in agreement in the upper atmosphere. The HCN mixing ratio is from $(1-3) \times 10^{-3}$ around $1000 \mathrm{~km}$. The density of HCN between 600 and $1000 \mathrm{~km}$ has been also inferred by Shemansky et al. (2005) from observations of stellar occultations by the atmosphere of Titan using the Cassini Ultraviolet Imaging Spectrometer (UVIS). The $\mathrm{HCN}$ mixing ratio at $1000 \mathrm{~km}$ is about $4 \times 10^{-3}$. Recently, Adriani et al. (2011) used the limb observations of the Visual and Infrared Mapping Spectrometer (VIMS) onboard the Cassini spacecraft to retrieve vertical profiles of $\mathrm{HCN}$ from its $3 \mu \mathrm{m}$ non-LTE emission in the region from 600 to $1100 \mathrm{~km}$ altitude at daytime. The mixing ratio of $\mathrm{HCN}$ is about $(5.5 \pm 1.5) \times 10^{-3}$ at $1050 \mathrm{~km}$. This result is in agreement with the upper value of the HCN profile derived by Yelle \& Griffith (2003) and Kim et al. (2005). HCN has been also detected in Titan's upper atmosphere in the ultraviolet by the UltraViolet Spectrometer (UVS) instrument aboard Voyager 1 (Vervack et al. 2004). The mixing ratio of $\mathrm{HCN}$ is around $10^{-4}$ at $500 \mathrm{~km}$ (about 20 times lower than other observations) and then increases with altitude leading to a value in agreement with all the other observations (but with large uncertainties).

It is difficult to compare all these observations taken at different times, using different techniques and corresponding to different spatial resolutions. In addition, these observations are more or less model-dependent and a direct comparison with our nominal profile is not straightforward. Due to the inconsistency of the published observational data (error bars do not overlap), we can conclude that our nominal neutral model, which does not include ions, is roughly consistent with these observations.

\subsubsection{Sensitivity to eddy diffusion}

If restricted above $1000 \mathrm{~km}$, the mixing ratio of $\mathrm{HNC}$ derived from observation of Moreno et al. (2011) is about $6 \times 10^{-5}$ and the mixing ratio of $\mathrm{HCN}$ is in the range $(0.2-6) \times 10^{-3}$ according the various observations. This leads to a $\mathrm{HNC} / \mathrm{HCN}$ ratio of about $0.01-0.3$. In our current model, the $\mathrm{HNC} / \mathrm{HCN}$ ratio is about 0.1 . At $500 \mathrm{~km}$, the $\mathrm{HNC} / \mathrm{HCN}$ ratio from the various observations is around $5 \times 10^{-3}$ (assuming a constant mixing ratio

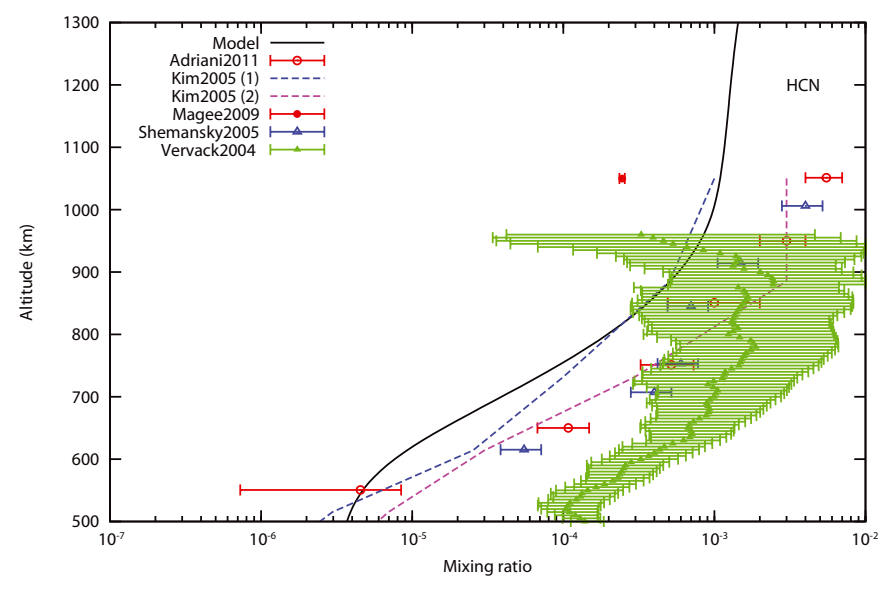

Fig. 3. Mixing ratio of $\mathrm{HCN}$ in the upper atmosphere of Titan. Model (solid line) and main observations in the upper atmosphere (see text for references).

of HNC above $500 \mathrm{~km}$ ). In our model, the ratio is $2 \times 10^{-5}$, more than 100 times lower.

Since the eddy diffusion coefficient is not well constrained in the atmosphere of Titan, we have tested other $K(z)$ profiles in order to test the sensitivity of this ratio to transport. For instance, in the case of the eddy diffusion profile $K(z)$ derived by Hörst et al. (2008), the methane homopause is located around $z_{\mathrm{h}}=800 \mathrm{~km}$ and $K_{\mathrm{h}}=3 \times 10^{7} \mathrm{~cm}^{2} \mathrm{~s}^{-1}$. In the case of the eddy diffusion profile $K(z)$ obtained by Strobel et al. (1992), the methane homopause is around $z_{\mathrm{h}}=1100 \mathrm{~km}$ and $K_{h}=10^{9} \mathrm{~cm}^{2} \mathrm{~s}^{-1}$. Figure 4 shows that the $\mathrm{HNC} / \mathrm{HCN}$ ratio is not sensitive to $K(z)$ down to $700 \mathrm{~km}$ but is different by a factor of 100 at $500 \mathrm{~km}$. At $500 \mathrm{~km}$, the discrepancy between our model using the $K(z)$ of Strobel et al. (1992) and observations is more pronounced since the ratio is only $3 \times 10^{-7}$.

$\mathrm{HNC}$ and $\mathrm{HCN}$ mixing ratios for the two eddy profiles are also presented in Fig. 4. Their abundances differ by a factor of 3 above $1000 \mathrm{~km}$. As explained in the following section, both $\mathrm{HNC}$ and $\mathrm{HCN}$ are mainly produced from the reaction of $\mathrm{H}_{2} \mathrm{CN}$, which is produced by the reaction between $\mathrm{N}\left({ }^{4} \mathrm{~S}\right)$ and $\mathrm{CH}_{3}$. So, these differences are directly linked to the mixing ratio of $\mathrm{CH}_{3}$ which depends on the photolysis and the molecular diffusion of $\mathrm{CH}_{4}$ above the homopause.

Consequently, the sensitivity of $\mathrm{HNC}$ and $\mathrm{HCN}$ to $K(z)$ is lower than the uncertainties on the model (see also Figs. 8 and 9) and can not be used to constrain the eddy diffusion coefficient profile in the upper atmosphere of Titan.

\subsection{Main production and loss processes for HNC}

The main production and loss processes for HNC (for the current chemical scheme) are presented in Fig. 5 and are listed in Table 2. Here we summarize the main processes leading to the production and loss of $\mathrm{HNC}$ from the primary radicals.

\subsubsection{Production}

At $1300 \mathrm{~km}, \mathrm{HNC}$ is produced from:

$\mathrm{H}_{2} \mathrm{CN}+\mathrm{H} \rightarrow \mathrm{HNC}+\mathrm{H}_{2}(64 \%)$

$\mathrm{N}\left({ }^{4} \mathrm{~S}\right)+{ }^{3} \mathrm{CH}_{2} \rightarrow \mathrm{HNC}+\mathrm{H}(34 \%)$.

At $1000 \mathrm{~km}, \mathrm{HNC}$ comes mainly from the reaction:

$\mathrm{H}_{2} \mathrm{CN}+\mathrm{H} \rightarrow \mathrm{HNC}+\mathrm{H}_{2}(98 \%)$. 
E. Hébrard et al.: Neutral production of HNC and HCN in Titan's upper atmosphere

Table 2. Main reactions for the production (top) and loss (bottom) of HNC.

\begin{tabular}{lcccccc}
\hline \hline \multirow{2}{*}{ Reaction } & \multicolumn{2}{c}{ Arrhenius coefficients } & \multicolumn{2}{c}{ Uncertainty } & Reference \\
& $\alpha$ & $\beta$ & $\gamma$ & $F_{0}$ & $g$ & \\
\hline $\mathrm{NH}+{ }^{3} \mathrm{CH}_{2} \rightarrow \mathrm{HNC}+\mathrm{H}_{2}$ & $5.0 \times 10^{-12}$ & 0.0 & 0.0 & 4.0 & 0 & This work \\
$\mathrm{H}_{2} \mathrm{CN}+\mathrm{H} \rightarrow \mathrm{HNC}+\mathrm{H}_{2}$ & $1.2 \times 10^{-11}$ & 0.0 & 0.0 & 3.0 & 14 & This work \\
$\mathrm{N}\left({ }^{4} \mathrm{~S}\right)+{ }^{3} \mathrm{CH}_{2} \rightarrow \mathrm{HNC}+\mathrm{H}$ & $3.0 \times 10^{-11}$ & 0.17 & 0.0 & 3.0 & 0 & This work \\
\hline $\mathrm{HNC}+\mathrm{H} \rightarrow \mathrm{HCN}+\mathrm{H}$ & $4.0 \times 10^{-11}$ & 0.0 & 1200 & 10.0 & 100 & This work \\
$\mathrm{HNC}+\mathrm{CH} \rightarrow \mathrm{CHCN}+\mathrm{H}$ & $1.4 \times 10^{-10}$ & -0.17 & 0.0 & 3.0 & 7 & Estimated from HCN $+\mathrm{CH}$ \\
$\mathrm{HNC}+\mathrm{CH} \rightarrow \mathrm{C}_{2} \mathrm{~N}+\mathrm{H}_{2}$ & $1.4 \times 10^{-10}$ & -0.17 & 0.0 & 3.0 & 7 & Estimated from HCN $+\mathrm{CH}$ \\
$\mathrm{N}\left({ }^{2} \mathrm{D}\right)+\mathrm{HNC} \rightarrow \mathrm{CN} \mathrm{H}_{2}+\mathrm{H}$ & $8.0 \times 10^{-11}$ & 0.0 & 0.0 & 10.0 & 0 & This work \\
$\mathrm{N}\left({ }^{2} \mathrm{D}\right)+\mathrm{HNC} \rightarrow \mathrm{CH}+\mathrm{N}_{2}$ & $8.0 \times 10^{-11}$ & 0.0 & 0.0 & 10.0 & 0 & This work \\
$\mathrm{CN}+\mathrm{HNC} \rightarrow \mathrm{C}_{2} \mathrm{~N}_{2}+\mathrm{H}$ & $2.0 \times 10^{-10}$ & 0.0 & 0.0 & 4.0 & 0 & This work \\
$\mathrm{HNC}+\mathrm{C}_{2} \mathrm{H} \rightarrow \mathrm{HC}_{3} \mathrm{~N}+\mathrm{H}$ & $1.75 \times 10^{-10}$ & 0.0 & 0.0 & 4.0 & 0 & This work \\
$\mathrm{HNC}+\mathrm{C}_{3} \mathrm{~N} \rightarrow \mathrm{C}_{4} \mathrm{~N}_{2}+\mathrm{H}$ & $2.0 \times 10^{-10}$ & 0.0 & 0.0 & 4.0 & 0 & This work \\
\hline
\end{tabular}

Notes. Reaction rates are expressed as $k=\alpha \times(T / 300)^{\beta} \times \exp (-\gamma / T) \mathrm{cm}^{3}$ molecule $\mathrm{e}^{-1} \mathrm{~s}^{-1}$. Uncertainties are $\operatorname{expressed}$ as $F(T)=F_{0} \times \exp (g \times$ $|1 / T-1 / 300|)(T$ in $\mathrm{K})$.

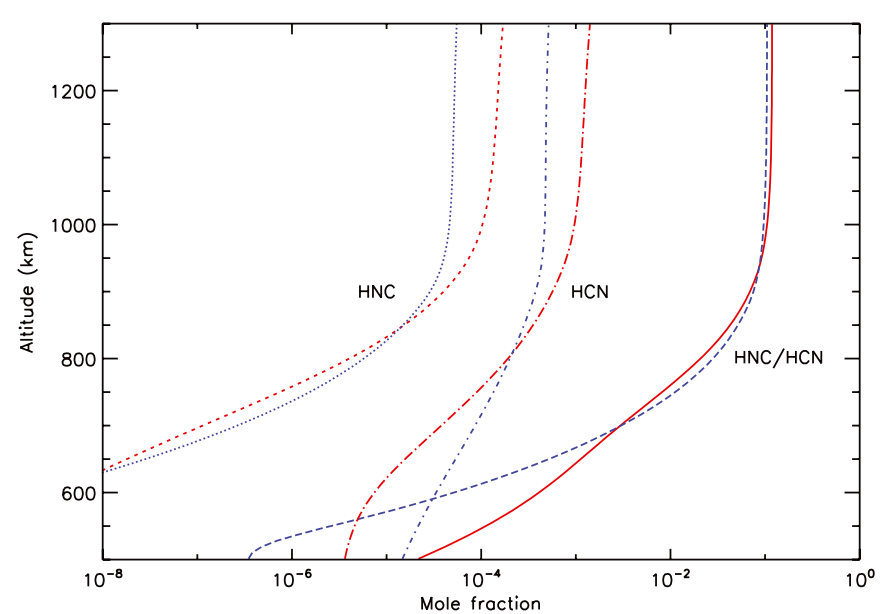

Fig. 4. Mixing ratios of $\mathrm{HNC}$ and $\mathrm{HCN}$ and $\mathrm{HNC} / \mathrm{HCN}$ ratio as a function of altitude for two eddy diffusion coefficients.

$\mathrm{H}_{2} \mathrm{CN}$ is mainly produced by two reactions:

$\mathrm{N}\left({ }^{4} \mathrm{~S}\right)+\mathrm{CH}_{3} \rightarrow \mathrm{H}_{2} \mathrm{CN}+\mathrm{H}(90 \%)$

$\mathrm{CH}_{2} \mathrm{NH}+\mathrm{h} v \rightarrow \mathrm{H}_{2} \mathrm{CN}+\mathrm{H}(9 \%)$

while $\mathrm{CH}_{2} \mathrm{NH}$ comes from:

$\mathrm{N}\left({ }^{2} \mathrm{D}\right)+\mathrm{CH}_{4} \rightarrow \mathrm{CH}_{2} \mathrm{NH}+\mathrm{H}(60 \%)$

$\mathrm{NH}+\mathrm{CH}_{3} \rightarrow \mathrm{CH}_{2} \mathrm{NH}+\mathrm{H}(35 \%)$

and NH comes from:

$\mathrm{N}\left({ }^{2} \mathrm{D}\right)+\mathrm{CH}_{4} \rightarrow \mathrm{NH}+\mathrm{CH}_{3}(64 \%)$

$\mathrm{N}\left({ }^{4} \mathrm{~S}\right)+\mathrm{H}_{2} \mathrm{CN} \rightarrow \mathrm{NH}+\mathrm{HCN}(21 \%)$

$\mathrm{N}\left({ }^{2} \mathrm{D}\right)+\mathrm{H}_{2} \rightarrow \mathrm{NH}+\mathrm{H}(11 \%)$.

At $600 \mathrm{~km}$, the scheme for the production of $\mathrm{HNC}$ is a little bit different; HNC comes fully from the reaction:

$\mathrm{H}_{2} \mathrm{CN}+\mathrm{H} \rightarrow \mathrm{HNC}+\mathrm{H}_{2}(100 \%)$

but $\mathrm{H}_{2} \mathrm{CN}$ is produced from:

$\mathrm{CH}_{2} \mathrm{NH}+\mathrm{h} v \rightarrow \mathrm{H}_{2} \mathrm{CN}+\mathrm{H}(74 \%)$

$\mathrm{CH}_{2} \mathrm{NH}+\mathrm{H} \rightarrow \mathrm{H}_{2} \mathrm{CN}+\mathrm{H}_{2}(22 \%)$
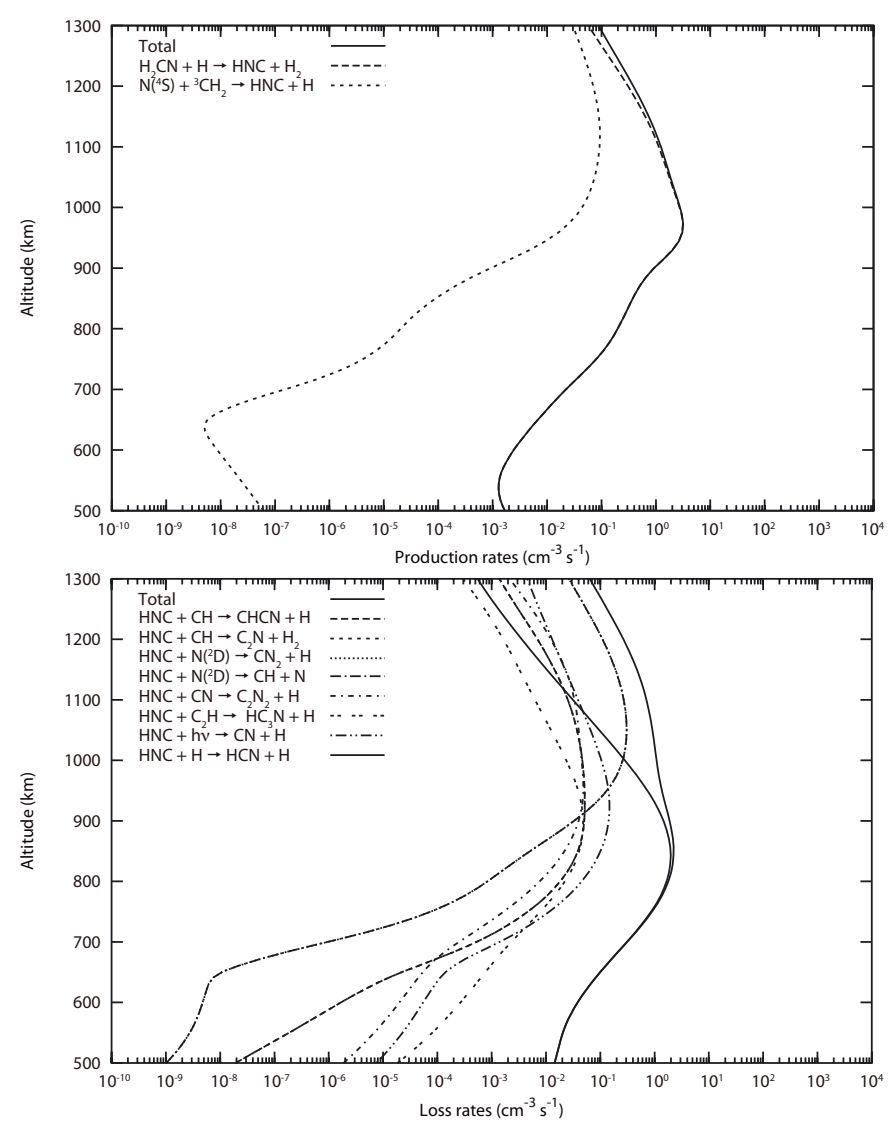

Fig. 5. Reaction rate profiles for most important reactions leading to the production and loss of HNC (see Table 2 for reactions).

and $\mathrm{CH}_{2} \mathrm{NH}$ comes from:

$\mathrm{CH}_{3} \mathrm{NH}_{2}+\mathrm{h} v \rightarrow \mathrm{CH}_{2} \mathrm{NH}+\mathrm{H}+\mathrm{H}(37 \%)$

$\mathrm{N}\left({ }^{2} \mathrm{D}\right)+\mathrm{CH}_{4} \rightarrow \mathrm{CH}_{2} \mathrm{NH}+\mathrm{H}(30 \%)$

$\mathrm{N}\left({ }^{2} \mathrm{D}\right)+\mathrm{C}_{2} \mathrm{H}_{6} \rightarrow \mathrm{CH}_{2} \mathrm{NH}+\mathrm{CH}_{3}(21 \%)$

$\mathrm{NH}+\mathrm{CH}_{3} \rightarrow \mathrm{CH}_{2} \mathrm{NH}+\mathrm{H}(11 \%)$.

As a conclusion, $\mathrm{H}_{2} \mathrm{CN}$ and $\mathrm{CH}_{2} \mathrm{NH}$ are key species in the production of $\mathrm{HNC}$ in the upper atmosphere of Titan. 


\subsubsection{Loss}

At $1300 \mathrm{~km}, \mathrm{HNC}$ is mainly destroyed by its reaction with $\mathrm{N}\left({ }^{2} \mathrm{D}\right)$ :

$\mathrm{N}\left({ }^{2} \mathrm{D}\right)+\mathrm{HNC} \rightarrow \mathrm{CN}_{2}+\mathrm{H}(41 \%)$

$\mathrm{N}\left({ }^{2} \mathrm{D}\right)+\mathrm{HNC} \rightarrow \mathrm{CH}+\mathrm{N}_{2}(41 \%)$.

At $1000 \mathrm{~km}$, the isomerization of $\mathrm{HNC}$ into $\mathrm{HCN}$ begins to contribute to the HNC loss as well:

$\mathrm{N}\left({ }^{2} \mathrm{D}\right)+\mathrm{HNC} \rightarrow \mathrm{CN}_{2}+\mathrm{H}(25 \%)$

$\mathrm{N}\left({ }^{2} \mathrm{D}\right)+\mathrm{HNC} \rightarrow \mathrm{CH}+\mathrm{N}_{2}(25 \%)$

$\mathrm{HNC}+\mathrm{H} \rightarrow \mathrm{HCN}+\mathrm{H}(24 \%)$.

At $600 \mathrm{~km}, \mathrm{HNC}$ is fully destroyed through its isomerization into $\mathrm{HCN}$ :

$\mathrm{HNC}+\mathrm{H} \rightarrow \mathrm{HCN}+\mathrm{H}(99 \%)$.

\subsection{Main production and loss processes for HCN}

The main production and loss processes for HCN are presented in Fig. 6 and are listed in Table 3. Here we summarize the main processes leading to the production and loss of $\mathrm{HCN}$ from the primary radicals.

\subsubsection{Production}

At $1300 \mathrm{~km}$, several reactions contribute to the production of $\mathrm{HCN}$ :

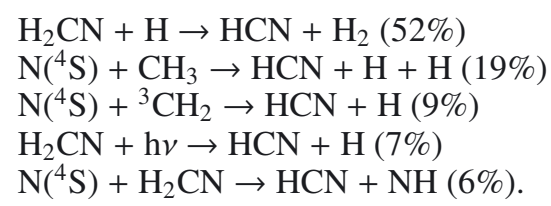

At $1000 \mathrm{~km}$, the situation is simpler, $\mathrm{HCN}$ comes from:

$\mathrm{H}_{2} \mathrm{CN}+\mathrm{H} \rightarrow \mathrm{HCN}+\mathrm{H}_{2}(78 \%)$

$\mathrm{N}\left({ }^{4} \mathrm{~S}\right)+\mathrm{CH}_{3} \rightarrow \mathrm{HCN}+\mathrm{H}+\mathrm{H}(9 \%)$

$\mathrm{C}_{2} \mathrm{~N}+\mathrm{H} \rightarrow \mathrm{HCN}+\mathrm{C}(7 \%)$.

In a similar manner to $\mathrm{HNC}$, the production of $\mathrm{HCN}$ is strongly related to the production of $\mathrm{H}_{2} \mathrm{CN}$. Again, the reaction between $\mathrm{N}\left({ }^{4} \mathrm{~S}\right)$ and $\mathrm{CH}_{3}$ is important since it produces both $\mathrm{H}_{2} \mathrm{CN}$ and $\mathrm{HCN}$.

At $600 \mathrm{~km}$, several reactions contribute equally to the production of HCN. Many of them involve $\mathrm{CN}$ radicals.

$$
\begin{aligned}
& \mathrm{CN}+\mathrm{C}_{2} \mathrm{H}_{6} \rightarrow \mathrm{HCN}+\mathrm{C}_{2} \mathrm{H}_{5}(25 \%) \\
& \mathrm{C}_{2} \mathrm{H}_{3} \mathrm{CN}+\mathrm{h} v \rightarrow \mathrm{C}_{2} \mathrm{H}_{2}+\mathrm{HCN}(24 \%) \\
& \mathrm{HNC}+\mathrm{H} \rightarrow \mathrm{HCN}+\mathrm{H}(16 \%) \\
& \mathrm{CN}+\mathrm{C}_{3} \mathrm{H}_{8} \rightarrow \mathrm{HCN}+\mathrm{C}_{3} \mathrm{H}_{7}(14 \%) \\
& \mathrm{C}_{2} \mathrm{~N}_{2}+\mathrm{H} \rightarrow \mathrm{HCN}+\mathrm{CN}(9 \%) \\
& \mathrm{CN}+\mathrm{CH}_{4} \rightarrow \mathrm{HCN}+\mathrm{CH}_{3}(6 \%) \\
& \mathrm{H}_{2} \mathrm{CN}+\mathrm{H} \rightarrow \mathrm{HCN}+\mathrm{H}_{2}(5 \%) .
\end{aligned}
$$

Where $\mathrm{C}_{2} \mathrm{H}_{3} \mathrm{CN}$ comes from:

$\mathrm{CN}+\mathrm{C}_{2} \mathrm{H}_{4} \rightarrow \mathrm{C}_{2} \mathrm{H}_{3} \mathrm{CN}+\mathrm{H}(99 \%)$.

And $\mathrm{CN}$ comes from:

$$
\begin{aligned}
& \mathrm{HCN}+\mathrm{h} v \rightarrow \mathrm{CN}+\mathrm{H}(23 \%) \\
& \mathrm{HC}_{3} \mathrm{~N}+\mathrm{h} v \rightarrow \mathrm{CN}+\mathrm{C}_{2} \mathrm{H}(55 \%) \\
& \mathrm{C}_{4} \mathrm{~N}_{2}+\mathrm{h} v \rightarrow \mathrm{C}_{3} \mathrm{~N}+\mathrm{CN}(15 \%) .
\end{aligned}
$$

As a conclusion, $\mathrm{H}_{2} \mathrm{CN}(z>1000 \mathrm{~km})$ and $\mathrm{CN}(z<1000 \mathrm{~km})$ are important intermediate compounds for the production of $\mathrm{HCN}$ in the upper atmosphere of Titan.
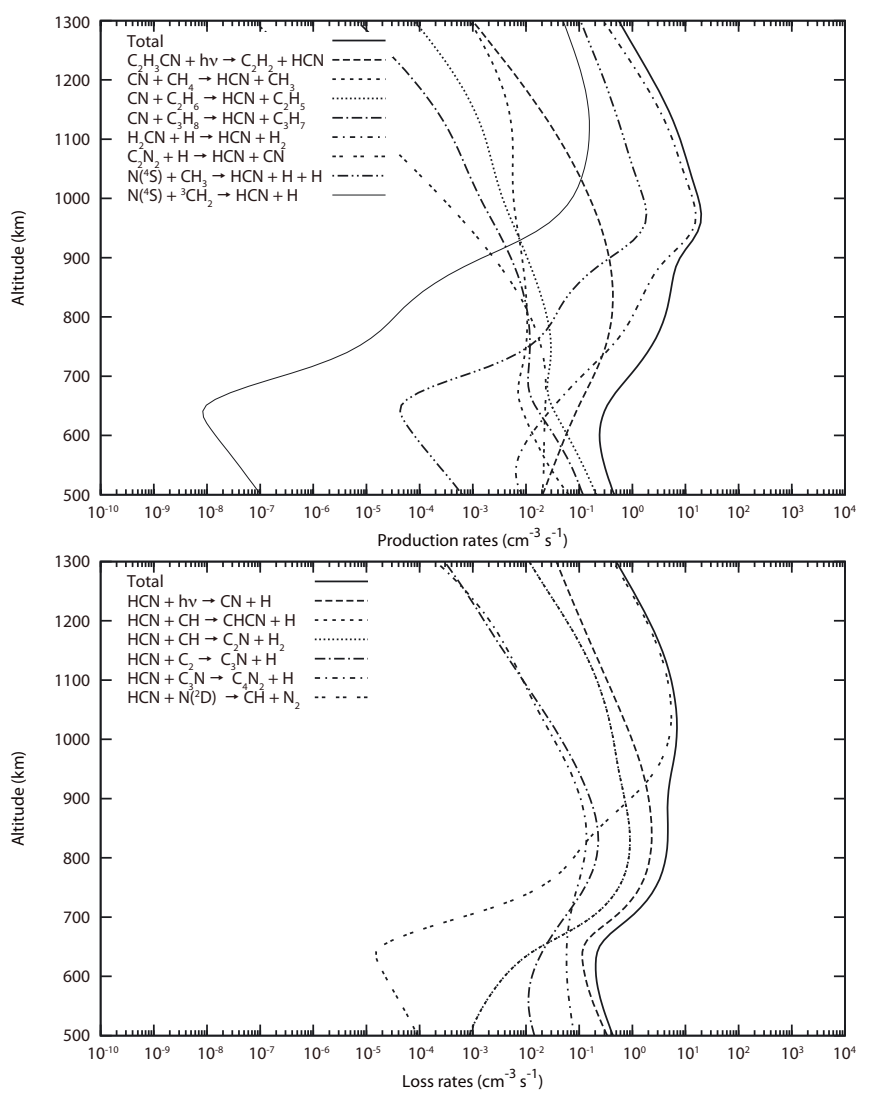

Fig. 6. Reaction rate profiles for most important reactions leading to the production and loss of HCN (see Table 3 for reactions).

\subsubsection{Loss}

At $1300 \mathrm{~km}, \mathrm{HCN}$ is mainly destroyed by its reaction with $\mathrm{N}\left({ }^{2} \mathrm{D}\right)$ and by its photolysis:

$\mathrm{N}\left({ }^{2} \mathrm{D}\right)+\mathrm{HCN} \rightarrow \mathrm{CH}+\mathrm{N}_{2}(88 \%)$

$\mathrm{HCN}+\mathrm{h} v \rightarrow \mathrm{CN}+\mathrm{H}(7 \%)$.

At $1000 \mathrm{~km}$, the situation is quite similar:

$\mathrm{N}\left({ }^{2} \mathrm{D}\right)+\mathrm{HCN} \rightarrow \mathrm{CH}+\mathrm{N}_{2}(72 \%)$

$\mathrm{HCN}+\mathrm{h} v \rightarrow \mathrm{CN}+\mathrm{H}(14 \%)$

$\mathrm{HCN}+\mathrm{CH} \rightarrow \mathrm{CHCN}+\mathrm{H}(6 \%)$

$\mathrm{HCN}+\mathrm{CH} \rightarrow \mathrm{C}_{2} \mathrm{~N}+\mathrm{H} 2(6 \%)$.

At $600 \mathrm{~km}, \mathrm{HCN}$ is partly destroyed through its reaction with $\mathrm{C}_{3} \mathrm{~N}$ radical:

$\mathrm{HCN}+\mathrm{h} v \rightarrow \mathrm{CN}+\mathrm{H}(62 \%)$

$\mathrm{HCN}+\mathrm{C}_{3} \mathrm{~N} \rightarrow \mathrm{C}_{4} \mathrm{~N}_{4}+\mathrm{H}(28 \%)$

$\mathrm{HCN}+\mathrm{C}_{2} \rightarrow \mathrm{C}_{3} \mathrm{~N}+\mathrm{H}(6 \%)$.

Remark. While studying the relative importance of the individual contribution of each reaction to the production and loss rates of a given compound, it is important to keep in mind the following fact: due to the large current uncertainties in reaction rates, the relative importance of each reaction might change drastically as we go along in the improvement of reaction rates accuracy at low temperature. As a consequence, the set of reactions given here for our current nominal model might not be the set of reactions that would dominate had some of the initial rate constants been different in the production or loss of HNC and HCN (see Sect. 6 for an illustration of the impact of uncertainties on reaction rates in model outputs). 
Table 3. Main reactions for the production (top) and loss (bottom) of HCN.

\begin{tabular}{lcccccc}
\hline \hline Reaction & \multicolumn{3}{c}{ Arrhenius coefficients } & \multicolumn{3}{c}{ Uncertainty } \\
& $\alpha$ & $\beta$ & $\gamma$ & $F_{0}$ & $g$ & Reference \\
& & & & & & \\
$\mathrm{C}_{2} \mathrm{H}_{3} \mathrm{CN}+\mathrm{h} \nu \rightarrow \mathrm{C}_{2} \mathrm{H}_{2}+\mathrm{HCN}$ & & & & & \\
$\mathrm{N}\left({ }^{4} \mathrm{~S}\right)+\mathrm{CH}_{3} \rightarrow \mathrm{HCN}+\mathrm{H}+\mathrm{H}$ & $6.0 \times 10^{-12}$ & 0.0 & 0.0 & 2.0 & 7 & This work \\
$\mathrm{CN}+\mathrm{CH}_{4} \rightarrow \mathrm{HCN}+\mathrm{CH}_{3}$ & $6.0 \times 10^{-12}$ & 0.0 & 721 & 1.6 & 0 & Yang et al. (1992); Sims et al. (1993) \\
$\mathrm{CN}+\mathrm{C}_{2} \mathrm{H}_{6} \rightarrow \mathrm{HCN}+\mathrm{C}_{2} \mathrm{H}_{5}$ & $2.08 \times 10^{-11}$ & 0.22 & -58 & 1.4 & 0 & Sims et al. (1993) \\
$\mathrm{CN}+\mathrm{C}_{3} \mathrm{H}_{8} \rightarrow \mathrm{HCN}+\mathrm{C}_{3} \mathrm{H}_{7}$ & $2.14 \times 10^{-11}$ & 1.19 & -378 & 1.4 & 0 & Yang et al. (1992) \\
$\mathrm{HNC}+\mathrm{H} \rightarrow \mathrm{HCN}+\mathrm{H}$ & $4.0 \times 10^{-11}$ & 0.0 & 1200 & 10.0 & 100 & This work \\
$\mathrm{C}_{2} \mathrm{~N}_{2}+\mathrm{H} \rightarrow \mathrm{HCN}+\mathrm{CN}$ & $8.59 \times 10^{-16}$ & 0.0 & 0.0 & 2.0 & 100 & Dunn et al. (1971) \\
$\mathrm{H}_{2} \mathrm{CN}+\mathrm{H} \rightarrow \mathrm{HCN}+\mathrm{H}_{2}$ & $6.0 \times 10^{-11}$ & 0.0 & 0.0 & 4.0 & 7 & This work \\
$\mathrm{N}\left({ }^{4} \mathrm{~S}\right)+{ }^{3} \mathrm{CH} \rightarrow \mathrm{HCN}+\mathrm{H}$ & $5.0 \times 10^{-11}$ & 0.17 & 0.0 & 3.0 & 0.0 & This work \\
\hline $\mathrm{HCN}+\mathrm{h} \nu \rightarrow \mathrm{CN}+\mathrm{H}$ & & & & & & \\
$\mathrm{HCN}+\mathrm{CH} \rightarrow \mathrm{CHCN}+\mathrm{H}$ & $1.4 \times 10^{-10}$ & -0.17 & 0.0 & 3.0 & 7 & This work \\
$\mathrm{HCN}+\mathrm{CH} \rightarrow \mathrm{C}_{2} \mathrm{~N}+\mathrm{H}_{2}$ & $1.4 \times 10^{-10}$ & -0.17 & 0.0 & 3.0 & 7 & This work \\
$\mathrm{HCN}+\mathrm{N}\left({ }^{2} \mathrm{D}\right) \rightarrow \mathrm{CH}+\mathrm{N}_{2}$ & $1.6 \times 10^{-10}$ & 0.0 & 0.0 & 10.0 & 0 & This work \\
$\mathrm{HCN}+\mathrm{C}_{2} \rightarrow \mathrm{C}_{3} \mathrm{~N}+\mathrm{H}$ & $2.0 \times 10^{-10}$ & 0.17 & 0.0 & 3.0 & 0 & This work \\
$\mathrm{HCN}+\mathrm{C}_{3} \mathrm{~N} \rightarrow \mathrm{C}_{4} \mathrm{~N}_{2}+\mathrm{H}$ & $2.0 \times 10^{-10}$ & 0.0 & 0.0 & 4.0 & 21 & This work \\
\hline
\end{tabular}

Notes. Reaction rates are expressed as $k=\alpha \times(T / 300)^{\beta} \times \exp (-\gamma / T) \mathrm{cm}^{3}$ molecule ${ }^{-1} \mathrm{~s}^{-1}$. Uncertainties are $\operatorname{expressed}$ as $F(T)=F_{0} \times \exp (g \times$ $|1 / T-1 / 300|)(T$ in $\mathrm{K})$.

\section{Local sensitivity analysis: a critical reaction study}

Figure 5 shows that the most important loss reaction for $\mathrm{HNC}$ around $500 \mathrm{~km}$ is the isomerization reaction $\mathrm{H}+\mathrm{HNC} \rightarrow$ $\mathrm{HCN}+\mathrm{H}$ (see also Table 3$)$. The reaction rate of this process is not very well known at low temperature $(\approx 150 \mathrm{~K})$ with an uncertainty factor that we estimate to be about 10 (see Appendix A). So, this reaction is clearly critical for the abundance of HNC in our model. In order to pinpoint the importance of this reaction, we performed a local sensitivity analysis, which consists of changing the rate of this reaction by a factor of 10 whilst keeping all other rates unchanged. It is important to note that this kind of study gives only incomplete information about the importance of this reaction. A global sensitivity analysis is required to study how the uncertainty of this reaction rate propagates in the model through the set of strongly coupled and non-linear differential equations (Dobrijevic et al. 2010b). Results are presented in Fig. 2. Whilst there is only a factor of 2 between the extreme $\mathrm{HNC}$ mole fractions at $1300 \mathrm{~km}$, the difference reaches a factor of $10^{5}$ at $500 \mathrm{~km}$. As a consequence, the poor knowledge of the rate of this reaction limits strongly the accuracy of photochemical models.

\section{Uncertainty propagation study}

\subsection{Method}

The methodology used to study the propagation of uncertainties in the model is described in Hébrard et al. (2007) and Hébrard et al. (2009). There are many sources of uncertainty in a 1D photochemical model. In the present study, we focus exclusively on its chemical sources through the uncertainties of the photodissociation and reaction rates. These uncertainties originate in their experimental or theoretical determination, and are generally quantified by a standard deviation or a relative uncertainty. Because of the profoundly non-linear nature of the photochemical model and the potentially large uncertainties displayed by many parameters, a linear uncertainty propagation is not expected to produce valid results. Propagation of distributions by Monte Carlo sampling is better adapted to such problems (BIPM et al. 2008, 2006). Due to the positivity constraint on these properties, their distributions are modeled by lognormal probability density functions:

$$
p(x)=\frac{1}{\sqrt{2 \pi} x \sigma} \exp \left(-\frac{(\ln x-\mu)^{2}}{\sigma^{2}}\right)
$$

with $\mu=\ln k(T)$, the logarithm of the nominal value of the reaction rate at temperature $T$, and $\sigma=\ln F(T)$, the logarithm of the geometric standard uncertainty $F(T)$ of the lognormal distribution. With these notations, the $67 \%$ confidence interval for a reaction rate at a given temperature is given as $[k(T) / F(T), k(T) \times F(T)]$.

Estimation of the uncertainty factor $F(T)$ of a reaction rate $k(T)$ at any given temperature follows an expression adapted from KIDA (Wakelam et al. 2012):

$F(T)=F(300 \mathrm{~K}) \exp \left|g\left(\frac{1}{T}-\frac{1}{300}\right)\right|$

where $F(300 \mathrm{~K})$ is the uncertainty in the rate constant $k(T)$ at $T=300 \mathrm{~K}$ and $g$ is the "uncertainty-extrapolating" coefficient defined for use with $F(300 \mathrm{~K})$ in the above expression to obtain the rate constant uncertainty $F(T)$ at different temperatures. These assigned uncertainty factors $F(300 \mathrm{~K})$ and $g$ are evaluated to construct the appropriate uncertainty factor, $F(T)$, following an approach based on the fact that rate constants are almost always known with a minimum uncertainty at room temperature. The knowledge of both $F(300 \mathrm{~K})$ and $g$ parameters allows to quantify the temperature-dependent uncertainties carried by each reaction rate present in the standard sets of reaction rates in a temperature range adequate for Titan's atmosphere.

Most of the reaction rate coefficients and their associated uncertainty factors used in the present study are extracted from our previous reviews (Hébrard et al. 2006; Hébrard et al. 2009). Reaction rates and uncertainties for new processes are estimated according to the methodology introduced in Sect. 3. The uncertainty factor is set to 1.2 for all the photodissociation rates for simplicity (see Peng et al. 2012, for a valuable discussion about uncertainties on photodissociation rates). We perform 1000 runs to have statistically significant results. The integration time for each run is set to $10^{11} \mathrm{~s}$ for simplicity and to limit the computation time. This time is sufficient to reach a steady state in the 


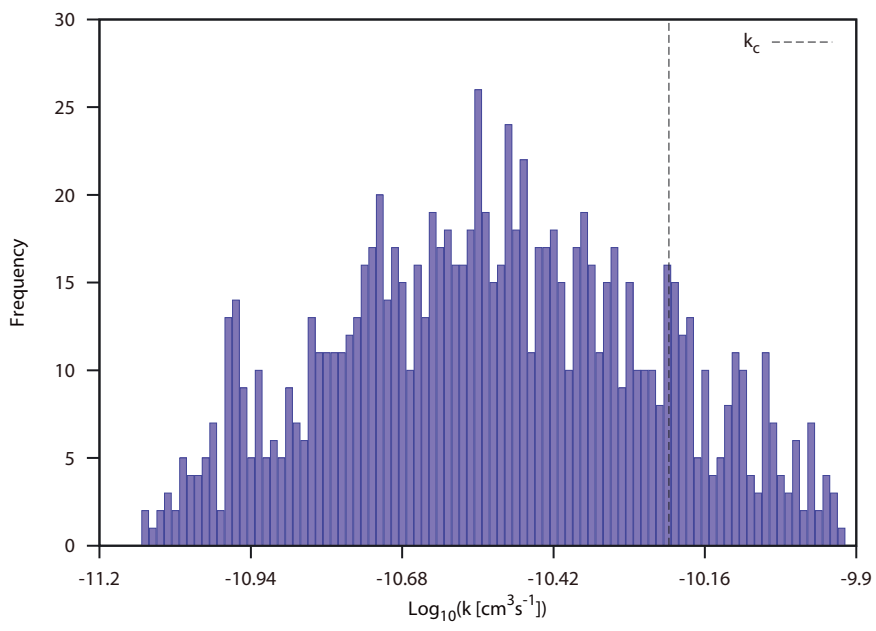

Fig. 7. Histograms of reaction rates obtained after 1000 runs for reaction $\mathrm{N}\left({ }^{4} \mathrm{~S}\right)+\mathrm{C}_{2} \mathrm{H} \rightarrow \mathrm{C}_{2} \mathrm{~N}+\mathrm{H}$. The reaction rate estimated for this reaction is $k_{\text {capture }}=6.0 \times 10^{-11}$ and its uncertainty factor is $F_{\text {capture }}=16$.

upper atmosphere. For instance, the most important relative variation of the HNC mole fractions is lower than $1.0 \times 10^{-2}$ for all the runs with very few exceptions.

Figure 7 presents an example of a rate constant histogram generated by our Monte-Carlo procedure for a reaction rate constant estimated by capture theory. As explained in Sect. 3, this kind of rate constant is in practice

$k=\gamma_{\mathrm{el}} \times k_{\text {capture }} / \sqrt{F_{\text {capture }}}$

and its uncertainty factor $F=\sqrt{F_{\text {capture }}}$. Our simulation is in good agreement with what was expected and we see that only a limited fraction of runs $(<15 \%)$ give rates greater than the $k_{\text {capture value. }}$

\subsection{Results: $H C N$ and HNC profiles}

The type of abundance distribution depends on the compound and can vary with altitude: distributions are not always normal or log-normal. In this case, quantiles are useful measures to represent the distributions. Figures 8 and 9 show the 5 th and 15 th of the 20-quantiles and the 1st and 19th of the 20-quantiles which give the intervals containing respectively $50 \%$ and $90 \%$ of the profiles.

The HCN and HNC profiles obtained from the uncertainty propagation study are presented in Fig. 8. We obtain large uncertainties for HNC, especially below $900 \mathrm{~km}$, whereas uncertainties are quite reasonable for $\mathrm{HCN}$ throughout the upper atmosphere. At $1300 \mathrm{~km}$, the mean value of the HNC mole fraction is $10^{-4}$ and $50 \%$ of the profiles lie between $5.3 \times 10^{-5}$ and $2.0 \times 10^{-4}$. For $\mathrm{HCN}$, the mean mole fraction is $1.2 \times 10^{-3}$ and $50 \%$ of the profiles lie between $8.0 \times 10^{-4}$ and $1.6 \times 10^{-3}$.

The $\mathrm{HNC} / \mathrm{HCN}$ ratio as a function of altitude is given in Fig. 9. The determination of this ratio is important with respect to the detection of $\mathrm{HCN}$ by the Cassini Ion Neutral Mass Spectrometer (INMS) (Magee et al. 2009). Since HNC and HCN have the same mass, it is likely that both species contributed significantly to the same peak in this instrument. We see in Fig. 9 that the ratio $\mathrm{HNC} / \mathrm{HCN}$ can statistically reach a value as high as 0.5 . More precisely, $90 \%$ of the $\mathrm{HNC} / \mathrm{HCN}$ profiles are within the range $[0.015,0.5]$ and $50 \%$ in the range $[0.04,0.17]$. By comparison with observations, Moreno et al. (2011) estimated that
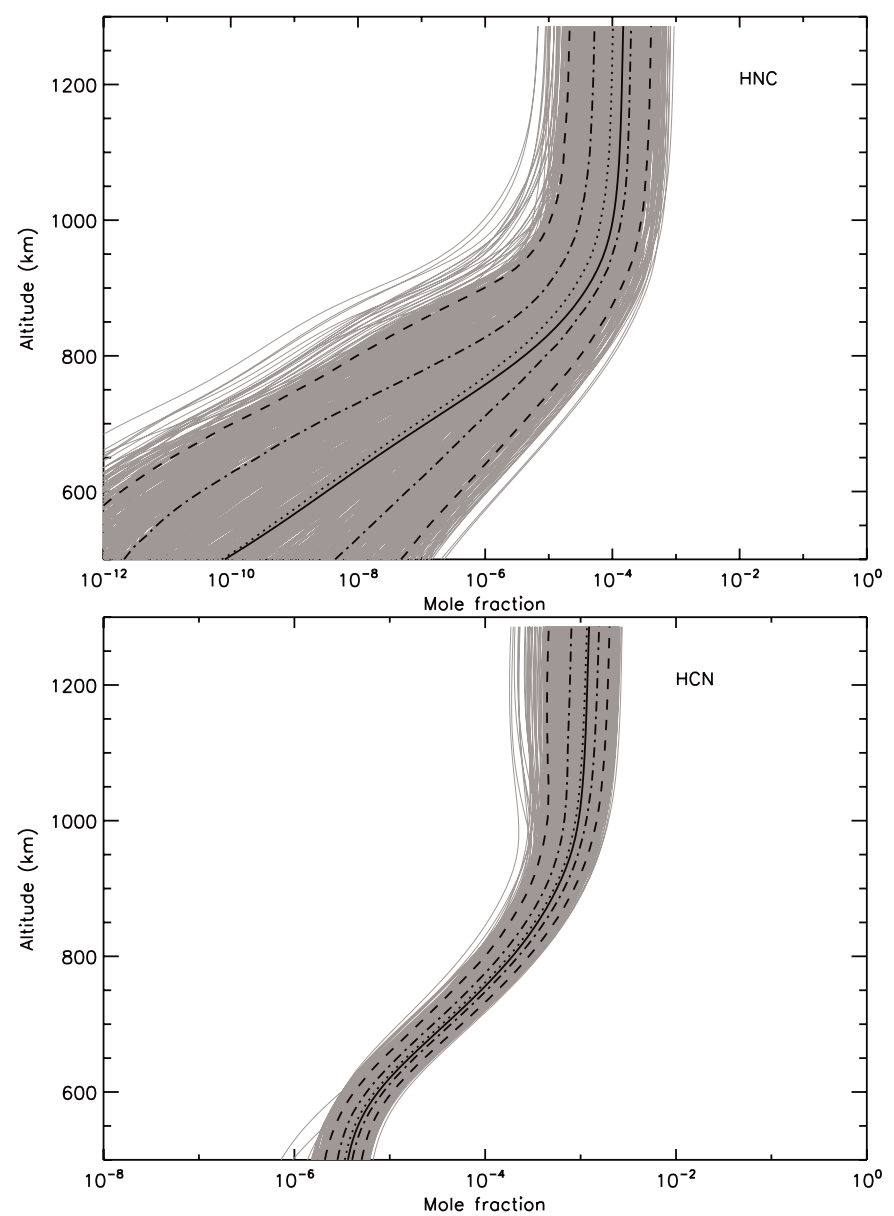

Fig. 8. Abundance profiles of $\mathrm{HNC}$ and $\mathrm{HCN}$ obtained after 1000 runs. Black solid line: initial profile. Black dotted line: median profile obtained from the uncertainty propagation study. Black dashed-dotted lines: 5th and 15th 20-quantiles of the distribution. Black long-dashed lines: 1st and 19th 20-quantiles of the distribution.

this ratio is about 0.3 (based on the abundance of $\mathrm{HCN}$ retrieved by INMS).

The main conclusion of these results is that the current accuracy of photochemical models for HNC is very poor, especially below $800 \mathrm{~km}$. Theoretical and experimental studies are required to improve the situation. We see in the next section that a global sensitivity analysis can pinpoint the key reactions that are responsible for these huge uncertainties.

\section{Global sensitivity analysis: determination of key reactions}

The technique we use is based on the computation of the Rank Correlation Coefficients (RCCs) between rate constants and abundances at different altitudes. It has been previously used and described in Carrasco et al. (2007); Dobrijevic et al. (2008); Hébrard et al. (2009). The greater the absolute value of a RCC is, the more important the contribution a given reaction rate has on the abundance uncertainty for a given species. As a consequence, all reactions with a high absolute value of RCC should be studied in priority to improve the accuracy of the model concerning $\mathrm{HNC}$ and HCN in the upper atmosphere of Titan. The power of this technique, based on the uncertainty propagation study and the knowledge of RCCs, to improve photochemical models has 
E. Hébrard et al.: Neutral production of HNC and HCN in Titan's upper atmosphere

Table 4. Key reactions responsible for HNC (top) and HCN (bottom) abundance uncertainties at $1000 \mathrm{~km}$ and $600 \mathrm{~km}$.

\begin{tabular}{lccccc}
\hline \hline Reaction & $F$ & $g$ & \multicolumn{3}{c}{ RCC } \\
& & & at $1300 \mathrm{~km}$ & at $1000 \mathrm{~km}$ & at $600 \mathrm{~km}$ \\
\hline $\mathrm{HNC}+\mathrm{H} \rightarrow \mathrm{HCN}+\mathrm{H}$ & 10.0 & 100 & 0.25 & -0.41 & -0.95 \\
$\mathrm{H}_{2} \mathrm{CN}+\mathrm{H} \rightarrow \mathrm{HCN}+\mathrm{H}_{2}$ & 2.0 & 14 & 0.39 & -0.40 & -0.12 \\
$\mathrm{H}_{2} \mathrm{CN}+\mathrm{H} \rightarrow \mathrm{HNC}+\mathrm{H}_{2}$ & 3.0 & 14 & 0.77 & 0.71 & 0.18 \\
$\mathrm{~N}\left({ }^{2} \mathrm{D}\right)+\mathrm{HNC} \rightarrow \mathrm{CN}_{2}+\mathrm{H}$ & 10.0 & 0 & -0.18 & -0.12 & - \\
$\mathrm{N}\left({ }^{2} \mathrm{D}\right)+\mathrm{HNC} \rightarrow \mathrm{CH}+\mathrm{N}_{2}$ & 10.0 & 0 & -0.16 & -0.11 & - \\
\hline $\mathrm{N}_{2}+\mathrm{h} \nu \rightarrow \mathrm{N}\left({ }^{2} \mathrm{D}\right)+\mathrm{N}\left({ }^{4} \mathrm{~S}\right)$ & & & - & - & 0.20 \\
$\mathrm{~N}\left({ }^{2} \mathrm{D}\right)+\mathrm{CH}_{4} \rightarrow \mathrm{CH}_{2} \mathrm{NH}+\mathrm{H}$ & 1.6 & 7 & - & 0.12 & 0.17 \\
$\mathrm{HCN}+\mathrm{CH} \rightarrow \mathrm{C}_{2} \mathrm{~N}+\mathrm{H}_{2}$ & 3.0 & 7 & - & - & -0.15 \\
$\mathrm{H}_{2} \mathrm{CN}+\mathrm{H} \rightarrow \mathrm{HCN}+\mathrm{H}_{2}$ & 2.0 & 14 & 0.28 & 0.29 & 0.16 \\
$\mathrm{H}_{2} \mathrm{CN}+\mathrm{H} \rightarrow \mathrm{HNC}+\mathrm{H}_{2}$ & 3.0 & 14 & -0.17 & -0.19 & - \\
$\mathrm{N}\left({ }^{2} \mathrm{D}\right)+\mathrm{HCN} \rightarrow \mathrm{CH}+\mathrm{N}_{2}$ & 10.0 & 0 & -0.85 & -0.83 & -0.78 \\
\hline
\end{tabular}

Notes. Only reactions with RCCs greater than 0.15 are given.

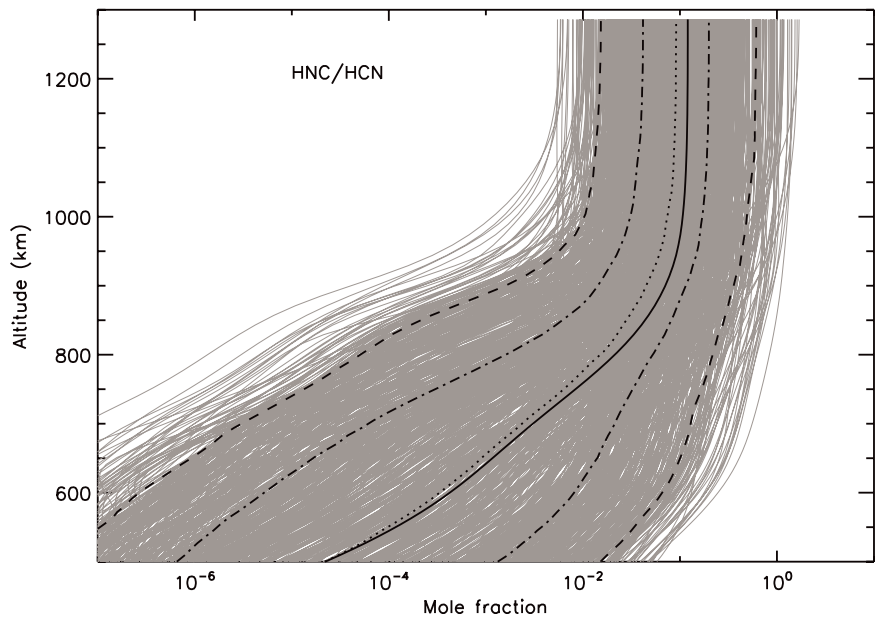

Fig. 9. Abundance profiles of $\mathrm{HNC} / \mathrm{HCN}$ ratios obtained after 1000 runs. Black solid line: initial profile. Black dotted line: median profile obtained from the uncertainty propagation study. Black dasheddotted lines: 5th and 15th 20-quantiles of the distribution. Black longdashed lines: 1st and 19th 20-quantiles of the distribution.

been demonstrated for Titan by Hébrard et al. (2009) and for Neptune by Dobrijevic et al. (2010a).

Among the few key reactions we give here, $\mathrm{H}_{2} \mathrm{CN}+\mathrm{H}$, $\mathrm{HNC}+\mathrm{H}$ and $\mathrm{N}\left({ }^{2} \mathrm{D}\right)+\mathrm{HNC} / \mathrm{HCN}$ are clearly the most important ones for $\mathrm{HNC}$ and $\mathrm{HCN}$ in the upper atmosphere of Titan. In Appendix A, we discuss in more details our current knowledge about these reactions.

\section{Conclusions}

Following the prediction of Petrie (2001), Moreno et al. (2011) concluded that a purely ionospheric source may be quantitatively viable for $\mathrm{HNC}$, provided that the protonation rates are not too high. Here we show that a purely neutral source is efficient enough to produce $\mathrm{HNC}$ and $\mathrm{HCN}$ in the upper atmosphere of Titan in agreement with current observations. Our study does not mean that ion-molecule mechanisms are not relevant to produce HNC but it shows that neutral reactions are competitive processes in the upper atmosphere and in the middle atmosphere as well.
The aim of the present work is to investigate as exhaustively as possible the neutral chemistry of $\mathrm{HNC}$ and $\mathrm{HCN}$ in order to construct a chemical scheme as complete as possible, to evaluate the uncertainties on the results that originate from the ones attached to the neutral reactions and to determine the key reactions that should be studied in priority to improve the model's precision regarding neutral chemistry. We show that the precision on the $\mathrm{HCN}$ abundance predicted by photochemical models is currently strongly limited by the poor knowledge of some reaction rates, especially the isomerization reaction $\mathrm{H}+\mathrm{HNC} \rightarrow \mathrm{HCN}+\mathrm{H}$. Further studies of the reactivity of $\mathrm{H}_{2} \mathrm{CN}$ with $\mathrm{H}$ and the reactivity of $\mathrm{N}\left({ }^{2} \mathrm{D}\right)$ with $\mathrm{HNC}$ and $\mathrm{HCN}$ are also very important.

Our results are a basis for studying the production and loss of HNC and HCN in the ionosphere of Titan. For instance, Krasnopolsky (2009) stated that $24 \%$ of the production of HCN comes from ion reactions, while ion reactions account only for $17 \%$ of the loss of HCN. More recently, Plessis et al. (2012) found that the production of $\mathrm{HCN}$ and $\mathrm{HNC}$ are about $5.9 \pm$ 2.5 molecule $\mathrm{cm}^{-3} \mathrm{~s}^{-1}$ and that $65 \%$ of this production comes from the dissociative recombination reaction $\mathrm{HCNH}^{+}+\mathrm{e}^{-}$. So, we can expect that the production of HCN and HNC should be greater than the production we find in the present study taking into account only neutral chemistry. However, we can also predict that uncertainties in ion-reaction rates might increase the uncertainty on HNC and HCN mole fractions obtained by the models. In conclusion, a coupled neutral and ion model is required to investigate the impact of ion chemistry on these compounds, to determine the uncertainties on the computed abundances and to pinpoint the key reactions involving ions.

Acknowledgements. The authors acknowledge partial financial support from the Observatoire Aquitain des Sciences de l'Univers (OASU), from the CNRS "Programme National de Planétologie" and from the CNRS interdisciplinary program "Environnements Planétaires et Origines de la Vie (EPOV)".

\section{Appendix A: Comments on selected reactions}

\section{A.1. $\mathrm{N}\left({ }^{4} \mathrm{~S}\right)+\mathrm{CH}_{3}$}

We have shown that the reaction $\mathrm{N}\left({ }^{4} \mathrm{~S}\right)+\mathrm{CH}_{3} \rightarrow$ products is of prime importance in the production of $\mathrm{H}_{2} \mathrm{CN}$, which appears to be a key compound for initiating both $\mathrm{HCN}$ and 
HNC chemistries in Titan's upper atmosphere. For this reason, we give in the following details our recommendation for the rate constant and the branching ratios.

The $\mathrm{N}\left({ }^{4} \mathrm{~S}\right)+\mathrm{CH}_{3}$ reaction has been studied experimentally down to $200 \mathrm{~K}$ (Marston et al. 1989a) showing a high value for the rate constant at $300 \mathrm{~K}(8.5 \pm$ 2.0) $\times 10^{-11} \mathrm{~cm}^{3}$ molecule $\mathrm{s}^{-1}$ with a complex negative temperature dependence. The authors propose two expressions for the global rate constant, $k(200-423 \mathrm{~K})=6.2 \times 10^{-11}+$ $2.2 \times 10^{-9} \exp (-1250 / T) \mathrm{cm}^{3}$ molecule ${ }^{-1} \mathrm{~s}^{-1}$ or $k(T)=4.3 \times$ $10^{-10} \exp (-420 / T) \mathrm{cm}^{3}$ molecule $\mathrm{s}^{-1}$. The second one deviates from the experimental results at low temperature and may underestimate the rate constant at temperatures representative of Titan's atmosphere. The possible exothermic exit channels are:

$$
\begin{aligned}
\mathrm{N}\left({ }^{4} \mathrm{~S}\right)+{ }^{2} \mathrm{CH}_{3} & \rightarrow{ }^{2} \mathrm{H}_{2} \mathrm{CN}+{ }^{2} \mathrm{H} & \Delta H_{r}(298 \mathrm{~K}) & =-153 \mathrm{~kJ} \mathrm{~mol}^{-1} \\
& \rightarrow{ }^{1} \mathrm{HCN}+{ }^{2} \mathrm{H}+{ }^{2} \mathrm{H} & \Delta H_{r}(298 \mathrm{~K}) & =-48 \mathrm{~kJ} \mathrm{~mol}^{-1} \\
& \rightarrow{ }^{1} \mathrm{HCN}+{ }^{1} \mathrm{H}_{2} & \Delta H_{r}(298 \mathrm{~K}) & =-484 \mathrm{~kJ} \mathrm{~mol}^{-1} \\
& \rightarrow{ }^{1} \mathrm{HNC}+{ }^{1} \mathrm{H}_{2} & \Delta H_{r}(298 \mathrm{~K}) & =-431 \mathrm{~kJ} \mathrm{~mol}^{-1} .
\end{aligned}
$$

Product branching ratios have been obtained for the $\mathrm{N}\left({ }^{4} \mathrm{~S}\right)+$ $\mathrm{CH}_{3}$ and $\mathrm{N}\left({ }^{4} \mathrm{~S}\right)+\mathrm{CD}_{3}$ reactions (Marston et al. 1989b) leading mainly to $\mathrm{H}_{2} \mathrm{CN}+\mathrm{H}$ formation $(85-100 \%)$ with some $\mathrm{HCN}$ formation $(0-15 \%)$. These authors suggest that $\mathrm{HCN}$ formation is associated with $\mathrm{H}_{2}$, however $\mathrm{HCN}+\mathrm{H}_{2}$ production is spinforbidden and needs intersystem crossing to occur. Additionally recent ab-initio calculations (Cimas \& Largo 2006) found almost $100 \%$ of $\mathrm{H}_{2} \mathrm{CN}$ production in good agreement with previous calculations (Nguyen et al. 1996). As $\mathrm{H}_{2} \mathrm{CN}$ may have enough internal energy $\left(153 \mathrm{~kJ} \mathrm{~mol}^{-1}\right)$ to overcome the dissociation barrier for $\mathrm{C}-\mathrm{H}$ dissociation $\left(130 \mathrm{~kJ} \mathrm{~mol}^{-1}\right)$, some $\mathrm{HCN}+\mathrm{H}+\mathrm{H}$ may be produced (Nguyen et al. 1996). The HCN obtained by Marston et al. (1989a) may also come from reaction of $\mathrm{H}_{2} \mathrm{CN}$ with atomic nitrogen (used in excess in their experiment) through $\mathrm{H}_{2} \mathrm{CN}+\mathrm{N}\left({ }^{4} \mathrm{~S}\right) \rightarrow \mathrm{HCN}+\mathrm{NH}$ or more likely through $\mathrm{H}_{2} \mathrm{CN}+\mathrm{N}\left({ }^{4} \mathrm{~S}\right) \rightarrow \mathrm{CH}_{2}+\mathrm{N}_{2}$ followed by $\mathrm{N}\left({ }^{4} \mathrm{~S}\right)+$ $\mathrm{CH}_{2} \rightarrow \mathrm{HCN}+\mathrm{H}$. We choose to recommend a rate constant value of $6.2 \times 10^{-11} \mathrm{~cm}^{3}$ molecule $\mathrm{s}^{-1}$ between $150 \mathrm{~K}$ and $200 \mathrm{~K}$ with a branching ratio equal to $90 \%$ for $\mathrm{H}_{2} \mathrm{CN}+\mathrm{H}$ formation and $10 \%$ for $\mathrm{HCN}+\mathrm{H}+\mathrm{H}$. Thus:

\begin{tabular}{lccc}
\hline \hline Reaction & $k\left(\mathrm{~cm}^{3}\right.$ molecule $\left.{ }^{-1} \mathrm{~s}^{-1}\right)$ & $F$ & $g$ \\
\hline $\mathrm{N}\left({ }^{4} \mathrm{~S}\right)+\mathrm{CH}_{3} \rightarrow \mathrm{H}_{2} \mathrm{CN}+\mathrm{H}$ & $5.6 \times 10^{-11}$ & 1.6 & 7 \\
$\mathrm{~N}\left({ }^{4} \mathrm{~S}\right)+\mathrm{CH}_{3} \rightarrow \mathrm{HCN}+\mathrm{H}+\mathrm{H}$ & $0.6 \times 10^{-11}$ & 2 & 7 \\
\hline
\end{tabular}

\section{A.2. $\mathrm{HCN} \rightarrow \mathrm{HNC}$ isomerization}

A specific problem in $\mathrm{HCN} / \mathrm{HNC}$ formation is the possibility of isomerization. The $\mathrm{HCN} \rightarrow \mathrm{HNC}$ isomerization barrier is calculated equal to $186 \mathrm{~kJ} \mathrm{~mol}^{-1}$, and the $\mathrm{HNC} \rightarrow \mathrm{HCN}$ isomerization barrier is calculated equal to $124 \mathrm{~kJ} \mathrm{~mol}^{-1}$ at the RCCST(T)/ccpVTZ level (DePrince III \& Mazziotti 2008). Some reactions producing $\mathrm{HCN}$ and all reactions producing $\mathrm{HNC}$ are highly exothermic. In Titan's atmosphere, relaxation occurs through collisional stabilization. The collisional stabilization time may be estimated (Forst 2003) as equal to $\frac{1}{3 \times 10^{-10} \times[M]} \approx 10^{-7} \mathrm{~s}$ at 1 Torr, much greater than the interconversion time-scale estimated as $<10^{-13} \mathrm{~s}$ (Herbst et al. 2000). Thus, as relaxation slowly occurs, isomerization leads to equilibrated isomeric abundances at each internal energy. The final balance is determined at or near the effective barrier for isomerization. As the available energy of the exothermic reactions producing $\mathrm{HCN}$ and $\mathrm{HNC}$ can be distributed among the translational and vibrational-rotational modes of both products, a fraction of
$\mathrm{HCN} / \mathrm{HNC}$ molecules will possess enough internal energy to overcome the isomerization barrier. To a first approximation we assumed roughly statistical distribution of energy in the fragments and consider that all of the $\mathrm{HCN}$ or HNC produced above the isomerization barrier will lead to equal amounts of $\mathrm{HCN}$ and HNC (Herbst et al. 2000).

The $\mathrm{HNC}+\mathrm{H} \rightarrow \mathrm{HCN}+\mathrm{H}$ reaction $\left(\Delta H_{r}(298 \mathrm{~K})=\right.$ $-53 \mathrm{~kJ} \mathrm{~mol}^{-1}$ ) has been calculated to possess a low barrier. The first estimation of the barrier was performed by Talbi \& Ellinger (1996) at a relatively high level of theory $(\mathrm{MP} 4 / 6-311++(3 \mathrm{df}, 2 \mathrm{p}) / / \mathrm{MP} 3 / 6-311++\mathrm{G}(\mathrm{d}, \mathrm{p}))$ with a best estimate value equal to $17.6 \pm 4 \mathrm{~kJ} \mathrm{~mol}^{-1}$. Sumathi \& Nguyen (1998) found a barrier equal to $13.8 \mathrm{~kJ} \mathrm{~mol}^{-1}$ at the CCSD(T)/6-311++(3df,3pd)//CCSD(T)/6-311++G(d,p) level and more recently Petrie (2002) found a value equal to $8.0 \mathrm{~kJ} \mathrm{~mol}^{-1}$ at the CBS/RAD or B3LYP/6-311G** level and $12.9 \mathrm{~kJ} \mathrm{~mol}^{-1}$ at the QCISD/6-311G* level. With estimated values between $8.0 \mathrm{~kJ} \mathrm{~mol}^{-1}(960 \mathrm{~K})$ and $18.0 \mathrm{~kJ} \mathrm{~mol}^{-1}$ $(2160 \mathrm{~K})$, the rate will be low, but not negligible, for relaxed $\mathrm{HNC}$. Moreover, as HNC is produced mainly with high internal energy there is a possibility of rate enhancement. For relaxed HNC we recommend the rate constant calculated by Sumathi \& Nguyen (1998) with an average value of the various calculations for the barrier including Petrie (2002):

\begin{tabular}{lccc}
\hline \hline Reaction & $k\left(\mathrm{~cm}^{3}\right.$ molecule $\left.{ }^{-1} \mathrm{~s}^{-1}\right)$ & $F$ & $g$ \\
\hline $\mathrm{H}+\mathrm{HNC} \rightarrow \mathrm{HCN}+\mathrm{H}$ & $4.03 \times 10^{-11} \times \exp (-1200 / T)$ & 10.0 & 100 \\
\hline
\end{tabular}

\section{A.3. $\mathrm{N}\left({ }^{2} \mathrm{D}\right)+\mathrm{CH}_{4}$}

The $\mathrm{N}\left({ }^{2} \mathrm{D}\right)+\mathrm{CH}_{4}$ reaction has been studied experimentally (Takayanagi et al. 1999; Umemoto et al. 1998) and theoretically (Ouk et al. 2011; Takayanagi \& Kurosaki 1999; Takayanagi et al. 1999) and a review has been performed by Herron (1999). Theoretical calculations suggest two pathways for this reaction, direct $\mathrm{H}$ atom abstraction and $\mathrm{N}\left({ }^{2} \mathrm{D}\right)$ insertion in one $\mathrm{C}-\mathrm{H}$ bond, both mechanism presenting a barrier in the entrance valley (Ouk et al. 2011; Takayanagi \& Kurosaki 1999; Takayanagi et al. 1999). It should be noted that ab-initio calculations with DFT and CCSD methods lead to the absence of a barrier for the insertion (Balucani et al. 2009). The $\mathrm{N}\left({ }^{2} \mathrm{D}\right)+\mathrm{CH}_{4}$ reaction has been studied experimentally in detail by Takayanagi et al. (1999) leading to $k(223-292 \mathrm{~K})=7.13 \times 10^{-11} \times$ $\exp (-755 / T) \mathrm{cm}^{3}$ molecule $\mathrm{s}^{-1}$.

$$
\begin{aligned}
\mathrm{N}\left({ }^{2} \mathrm{D}\right)+{ }^{1} \mathrm{CH}_{4} & \rightarrow{ }^{1} \mathrm{CH}_{2} \mathrm{NH}+{ }^{2} \mathrm{H} & \Delta H_{r}(298 \mathrm{~K})=-318 \mathrm{~kJ} \mathrm{~mol}^{-1} \\
& \rightarrow{ }^{2} \mathrm{CH}_{3}+{ }^{3} \mathrm{NH} & \Delta H_{r}(298 \mathrm{~K})=-126 \mathrm{~kJ} \mathrm{~mol}^{-1}
\end{aligned}
$$

Umemoto et al. (1998) found a ratio between $\mathrm{H}_{2} \mathrm{CNH}+\mathrm{H} / \mathrm{NH}+$ $\mathrm{CH}_{3}$ equal to $0.8 / 0.3$. Balucani et al. (2009) studied this reaction in a crossed beam experiment at high collision energy (above $22 \mathrm{~kJ} \mathrm{~mol}^{-1}$ which corresponds to $T>2600 \mathrm{~K}$ ) suggesting an increasing $\mathrm{NH}$ branching ratio with the temperature and also $\mathrm{H}_{2} \mathrm{CNH}$ and $\mathrm{CH}_{3} \mathrm{~N}$ production. As their results are ambiguous and correspond to high collisional energies, we preferred to use the Herron (1999) average value for the global rate constant (there is a typographical error in the Herron paper: it should be $A=4.8 \times 10^{-11}$ instead of $4.8 \times 10^{-12}$ in Table 3 ) associated with Umemoto et al. (1998) branching ratios:

\begin{tabular}{lccc}
\hline \hline Reaction & $k\left(\mathrm{~cm}^{3}\right.$ molecule $\left.{ }^{-1} \mathrm{~s}^{-1}\right)$ & $F$ & $g$ \\
\hline $\mathrm{N}\left({ }^{2} \mathrm{D}\right)+\mathrm{CH}_{4} \rightarrow \mathrm{CH}_{2} \mathrm{NH}+\mathrm{H}$ & $3.5 \times 10^{-11} \times \exp (-755 / T)$ & 1.6 & 7 \\
$\mathrm{~N}\left({ }^{2} \mathrm{D}\right)+\mathrm{CH}_{4} \rightarrow \mathrm{CH}_{3}+\mathrm{NH}$ & $1.3 \times 10^{-11} \times \exp (-755 / T)$ & 1.6 & 7 \\
\hline
\end{tabular}




\section{A.4. $\mathrm{H}+\mathrm{H}_{2} \mathrm{CN}$}

The $\mathrm{H}+\mathrm{H}_{2} \mathrm{CN}$ reaction is a key reaction for both $\mathrm{HCN}$ and HNC production. The rate constant for this reaction has been measured to be greater than $7 \times 10^{-11} \mathrm{~cm}^{3}$ molecule ${ }^{-1} \mathrm{~s}^{-1}$ (Nesbitt et al. 1990) and the authors also determined $\mathrm{HD} /(\mathrm{HCN}+\mathrm{HNC})$ branching ratios for the $\mathrm{H}+\mathrm{D}_{2} \mathrm{CN}$ reaction, leading to $\mathrm{HD} /(\mathrm{HCN}+\mathrm{HNC})=5 \pm 3$. This reaction has two exothermic bimolecular exit channels:

$$
\begin{array}{rll}
{ }^{2} \mathrm{H}_{2} \mathrm{CN}+{ }^{2} \mathrm{H} & \rightarrow{ }^{1} \mathrm{H}_{2}+{ }^{1} \mathrm{HNC} & \Delta H_{r}(298 \mathrm{~K})=-276 \mathrm{~kJ} \mathrm{~mol}^{-1} \\
& \rightarrow{ }^{1} \mathrm{H}_{2}+{ }^{1} \mathrm{HCN} & \Delta H_{r}(298 \mathrm{~K})=-331 \mathrm{~kJ} \mathrm{~mol}^{-1} .
\end{array}
$$

Previous theoretical calculations (Nguyen et al. 1996; Larson et al. 2006) show no barrier in the entrance valley for $\mathrm{H}_{2} \mathrm{CNH}$ formation. We performed new ab-initio calculations at the DFT/M06-2X/vtz and MRCI+Q/vqz levels (Loison et al., in prep.) showing unambiguously that $\mathrm{H}_{2} \mathrm{CNH}$ formation occurs in addition to the direct $\mathrm{H}$ atom abstraction without barriers in the entrance valley. The only possible evolution of the $\mathrm{H}_{2} \mathrm{CNH}$ molecule is back-dissociation or $\mathrm{H}_{2}+\mathrm{HNC}$ formation, the $\mathrm{H}_{2}+\mathrm{HCN}$ exit channel involving a high energy exit barrier located well above the reactant energy and therefore forbidden at 150-200 K. $\mathrm{H}_{2}+\mathrm{HNC}$ production also involves a high exit barrier calculated close to the energy level of the reactants. The position of the transition state TS varies with the calculation level and has been found to range between $+15 \mathrm{~kJ} \mathrm{~mol}^{-1}$ and $-9 \mathrm{~kJ} \mathrm{~mol}^{-1}$ by comparison with the reactants energy (Zhou \& Schlegel 2009; Nguyen et al. 1996). As this energy is critical to estimate HNC production, we calculate it at the MRCI+Q/vqz + $\mathrm{ZPE}(\mathrm{DFT} / \mathrm{M} 06-2 \mathrm{X} / \mathrm{vtz}$ ) level leading to a TS energy equal to $-9 \mathrm{~kJ} \mathrm{~mol}^{-1}$ below the reactants energy. To estimate the amount of HNC formed, we performed RRKM calculations (Loison et al., in prep.) with a TS energy given by the MRCI+Q/vqz calculations and the geometry and vibrational frequencies obtained at the DFT/M06-2X/vtz level. The main exit channel of the $\mathrm{H}_{2} \mathrm{CNH}$ adduct is found to be back-dissociation with a yield greater than $90 \%$ except at high pressure when the three body stabilisation plays a role. This corresponds to pressures above those relevant for Titan's upper atmosphere where $\mathrm{H}_{2} \mathrm{CN}$ is supposed to be present at high altitude. For the $\mathrm{H}+\mathrm{D}_{2} \mathrm{CN}$ results of Nesbitt et al. (1990) we attribute the $m / e=3$ signal, due to the HD molecule, to direct $\mathrm{D}$ atom abstraction, and the $m / e=27$ signal, due to $\mathrm{HNC}$ (and also $\mathrm{HCN}$ coming from HNC isomerization), to the $\mathrm{H}+\mathrm{H}_{2} \mathrm{CN} \rightarrow \mathrm{H}_{2} \mathrm{CNH} \rightarrow \mathrm{H}_{2}+\mathrm{HNC}$ pathway. Our RRKM calculations are then in reasonable agreement with experimental results considering the various uncertainties, particularly regarding the TS energy value. However additional uncertainties arise from the difference between the $\mathrm{H}_{2} \mathrm{CNH} \rightarrow \mathrm{H}_{2}+\mathrm{HNC}$ and $\mathrm{D}_{2} \mathrm{CNH} \rightarrow \mathrm{D}_{2}+\mathrm{HNC}$ dissociation rate constants, and also from the fact that $\mathrm{HCN}$ and $\mathrm{HNC}$ will be produced partly above the $\mathrm{HCN} \rightleftharpoons \mathrm{HNC}$ isomerization barrier. Considering a roughly statistical energy distribution in HNC and $\mathrm{HCN}$, we estimate $20 \%$ of total HNC production. For the global rate constant, we chose the experimental one even if it is only a minimum value.

\begin{tabular}{lccc}
\hline \hline Reaction & $k\left(\mathrm{~cm}^{3}\right.$ molecule & & \\
\hline $\mathrm{H}+\mathrm{H}_{2} \mathrm{CN} \rightarrow \mathrm{H}_{2}+\mathrm{HCN}$ & $6 \times 10^{-11}$ & $F$ & $g$ \\
$\mathrm{H}+\mathrm{H}_{2} \mathrm{CN} \rightarrow \mathrm{H}_{2}+\mathrm{HNC}$ & $1.2 \times 10^{-11}$ & 2 & 14 \\
\hline
\end{tabular}

\section{A.5. $\mathrm{N}\left({ }^{4} \mathrm{~S}\right)+\mathrm{H}_{2} \mathrm{CN}$}

There is one experimental determination of the rate constant between $200 \mathrm{~K}$ and $363 \mathrm{~K}$ (Nesbitt et al. 1990) and one indirect branching ratio determination (Marston et al. 1989b). The possible exit channels are:

$$
\begin{array}{rlr}
{ }^{2} \mathrm{H}_{2} \mathrm{CN}+\mathrm{N}\left({ }^{4} \mathrm{~S}\right) & \rightarrow{ }^{3} \mathrm{CH}_{2}+{ }^{1} \mathrm{~N}_{2} & \Delta H_{r}(298 \mathrm{~K})=-331 \mathrm{~kJ} \mathrm{~mol}^{-1} \\
& \rightarrow{ }^{3} \mathrm{NH}+{ }^{1} \mathrm{HCN} & \Delta H_{r}(298 \mathrm{~K})=-229 \mathrm{~kJ} \mathrm{~mol}^{-1} \\
& \rightarrow{ }^{1} \mathrm{H}_{2}+{ }^{3} \mathrm{CNN} & \Delta H_{r}(298 \mathrm{~K})=-150 \mathrm{~kJ} \mathrm{~mol}^{-1}
\end{array}
$$

Cimas \& Largo (2006) performed ab-initio calculations and found a small barrier for direct $\mathrm{H}$ atom abstraction, located at $11 \mathrm{~kJ} \mathrm{~mol}^{-1}$ at the CCSD/p-vtz level but at $-13 \mathrm{~kJ} \mathrm{~mol}^{-1}$ at the G2 level. This negative barrier is due to the ZPE variation. We performed calculations at the UHF-M06-2X/VTZ level and also found a barrier for direct abstraction $\left(+6.4 \mathrm{~kJ} \mathrm{~mol}^{-1}\right.$ without ZPE and $-3.6 \mathrm{~kJ} \mathrm{~mol}^{-1}$ including ZPE). No barrier was found for $\mathrm{H}_{2} \mathrm{CNN}$ adduct formation quickly leading to $\mathrm{CH}_{2}+\mathrm{N}_{2}$ formation. The good agreement between the calculated reaction enthalpy and the value derived from thermochemical data at $298 \mathrm{~K}$ (Baulch et al. 2005) gives us confidence in the calculations and in our conclusion that $\mathrm{CH}_{2}+\mathrm{N}_{2}$ is an open exit channel. There is a large uncertainty about $\mathrm{NH}+\mathrm{HCN}$ production however which is likely to be a minor but non negligible exit channel between 150 and $200 \mathrm{~K}$.

Marston et al. (1989b) found that HCN (and/or HNC) formation is the main product in the $\mathrm{N}\left({ }^{4} \mathrm{~S}\right)+\mathrm{CH}_{3}$ system, HCN being attributed to the result of the reaction sequence $\mathrm{N}\left({ }^{4} \mathrm{~S}\right)+$ $\mathrm{CH}_{3} \rightarrow \mathrm{H}+\mathrm{H}_{2} \mathrm{CN}$ followed by $\mathrm{N}\left({ }^{4} \mathrm{~S}\right)+\mathrm{H}_{2} \mathrm{CN} \rightarrow \mathrm{NH}+\mathrm{HCN}$. However in their experiment, $\mathrm{N}\left({ }^{4} \mathrm{~S}\right)$ was in excess and the $\mathrm{HCN}$ could have been the result of the reaction sequence $\mathrm{N}\left({ }^{4} \mathrm{~S}\right)+$ $\mathrm{CH}_{3} \rightarrow \mathrm{H}+\mathrm{H}_{2} \mathrm{CN}$ followed by $\mathrm{N}\left({ }^{4} \mathrm{~S}\right)+\mathrm{H}_{2} \mathrm{CN} \rightarrow \mathrm{CH}_{2}+\mathrm{N}_{2}$ and $\mathrm{N}\left({ }^{4} \mathrm{~S}\right)+\mathrm{CH}_{2} \rightarrow \mathrm{H}+\mathrm{HCN} / \mathrm{HNC}$. The experimental rate constant $\left(k(T)=1.0 \times 10^{-10} \times \exp (-200 / T) \mathrm{cm}^{3}\right.$ molecule ${ }^{-1} \mathrm{~s}^{-1}$ in the 200-363 $\mathrm{K}$ range) has large uncertainties (Nesbitt et al. 1990) and cannot be extrapolated to low temperature as it may be the result of the two reaction channels including the direct abstraction with a barrier. We point out that a simple capture rate model, with the dispersion term only, leads to a rate constant equal to $k\left(\mathrm{~N}\left({ }^{4} \mathrm{~S}\right)+\mathrm{H}_{2} \mathrm{CN}\right)=4.5 \times 10^{-10} \times(T / 300)^{0.17} \times$ $(3 / 8)=1.7 \times 10^{-10} \times(T / 300)^{0.17} \mathrm{~cm}^{3}$ molecule $\mathrm{c}^{-1} \mathrm{~s}^{-1}, 4$ times higher than the experimental rate constant equal to $4.4 \times$ $10^{-11} \mathrm{~cm}^{3}$ molecule ${ }^{-1} \mathrm{~s}^{-1}$ at $300 \mathrm{~K}$. Considering the uncertainties in the experimental results we propose:

\begin{tabular}{llll}
\hline \hline Reaction & $k\left(\mathrm{~cm}^{3}\right.$ molecule $\left.^{-1} \mathrm{~s}^{-1}\right)$ & $F$ & $g$ \\
\hline $\mathrm{N}\left({ }^{4} \mathrm{~S}\right)+\mathrm{H}_{2} \mathrm{CN} \rightarrow \mathrm{NH}+\mathrm{HCN}$ & $1.0 \times 10^{-11}$ & 4 & 0 \\
$\mathrm{~N}\left({ }^{4} \mathrm{~S}\right)+\mathrm{H}_{2} \mathrm{CN} \rightarrow \mathrm{N}_{2}+\mathrm{CH}_{2}$ & $3.0 \times 10^{-11}$ & 3 & 0 \\
\hline
\end{tabular}

\section{A.6. $\mathrm{HCN}+\mathrm{CH}$}

The total rate constant for this reaction has been measured between 296 and $674 \mathrm{~K}$ equal to $(5.0 \pm 0.4) \times 10^{-11} \times$ $\exp ((500 \pm 30) / T) \mathrm{cm}^{3}$ molecule $\mathrm{e}^{-1} \mathrm{~s}^{-1}$ (Zabarnick et al. 1991). This expression cannot be extrapolated to low temperature as it yields unrealistically large values. The measured $k(296 \mathrm{~K})$ is equal to $2.7 \times 10^{-10} \mathrm{~cm}^{3}$ molecule ${ }^{-1} \mathrm{~s}^{-1}$. A simple capture treatment leads to a high rate constant (close to $6.0 \times$ $10^{-10} \mathrm{~cm}^{3}$ molecule $\mathrm{s}^{-1}$ at $298 \mathrm{~K}$ ) due to the strong dipoledipole interaction. We propose to scale the capture rate constant to the value at room temperature and to conserve the temperature dependence appropriate for the dipole-dipole interaction, leading to $k(T)=2.7 \times 10^{-10} \times(T / 300)^{-0.17} \mathrm{~cm}^{3}$ molecule ${ }^{-1} \mathrm{~s}^{-1}$. Theoretical calculations (Du \& Zhang 2006) show no barrier for $\mathrm{H}_{2} \mathrm{CCN}$ formation through $\mathrm{CH}+\mathrm{HCN} \rightarrow \mathrm{HCC}(\mathrm{H}) \mathrm{N} \rightarrow$ $\mathrm{H}_{2} \mathrm{CCN}$. $\mathrm{H}_{2} \mathrm{CCN}$ can lead subsequently to

$$
\begin{aligned}
{ }^{1} \mathrm{HCN}+{ }^{2} \mathrm{CH} & \rightarrow{ }^{3} \mathrm{HCCN}+{ }^{2} \mathrm{H} & \Delta H_{r}(298 \mathrm{~K})=-23 \mathrm{~kJ} \mathrm{~mol}^{-1} \\
& \rightarrow{ }^{1} \mathrm{H}_{2}+{ }^{2} \mathrm{CCN} & \Delta H_{r}(298 \mathrm{~K})=-42 \mathrm{~kJ} \mathrm{~mol}^{-1}
\end{aligned}
$$

Osamura \& Petrie (2004) have determined that H + HCCN production has no barrier in the exit channel and that $\mathrm{H}_{2}+\mathrm{CCN}$ production exhibits a tight TS located only $6 \mathrm{~kJ} \mathrm{~mol}^{-1}$ above this 
exit channel. These two exit channels should therefore have similar branching ratios to a first approximation, even if RRKM calculations are necessary to estimate more precisely their value.

\begin{tabular}{lccc}
\hline \hline Reaction & $k\left(\mathrm{~cm}^{3}\right.$ molecule $\left.^{-1} \mathrm{~s}^{-1}\right)$ & $F$ & $g$ \\
\hline $\mathrm{HCN}+\mathrm{CH} \rightarrow \mathrm{HCCN}+\mathrm{H}$ & $1.4 \times 10^{-10} \times(T / 300)^{-0.17}$ & 3.0 & 7 \\
$\mathrm{HCN}+\mathrm{CH} \rightarrow \mathrm{H}_{2}+\mathrm{CCN}$ & $1.4 \times 10^{-10} \times(T / 300)^{-0.17}$ & 3.0 & 7 \\
\hline
\end{tabular}

\section{A.7. $\left.\mathrm{N}^{2} \mathrm{D}\right)+\mathrm{HCN}$}

The first electronically excited state of atomic nitrogen, $N\left({ }^{2} \mathrm{D}\right)$ is known to react quickly with most radicals and molecules (Herron 1999). We performed ab-initio calculations at various levels for $\mathrm{N}\left({ }^{2} \mathrm{D}\right)$ attack on $\mathrm{HCN}$ in $\mathrm{C}_{\mathrm{s}}$ and $\mathrm{C}_{2 \mathrm{v}}$ symmetry. The most attractive pathways have been found at MRCI+Q/vtz and R-CCSD(T)/vtz levels for $\mathrm{C}_{2 \mathrm{v}}$ geometry for which the ${ }^{2} \mathrm{~B}_{1}$ and ${ }^{2} \mathrm{~B}_{2}$ states show no barrier for $\mathrm{HCNN}$ adduct formation. The similar results for both methods coupled to the very good agreement between experiments (Ralchenko et al. 2011) and our calculations at the $\mathrm{MRCI}+\mathrm{Q} / \mathrm{vtz}$ level for $\mathrm{N}\left({ }^{4} \mathrm{~S}\right) / \mathrm{N}\left({ }^{2} \mathrm{D}\right) / \mathrm{N}\left({ }^{2} \mathrm{P}\right)$ relative energies lead us to predict no barrier for this reaction. Further evolution of the adduct can lead to:

$$
\begin{aligned}
\mathrm{N}\left({ }^{2} \mathrm{D}\right)+{ }^{1} \mathrm{HCN} & \rightarrow{ }^{2} \mathrm{H}+{ }^{3} \mathrm{NCN} & \Delta H_{r}(298 \mathrm{~K})=-154 \mathrm{~kJ} \mathrm{~mol}^{-1} \\
& \rightarrow{ }^{2} \mathrm{CH}+{ }^{1} \mathrm{~N}_{2} & \Delta H_{r}(298 \mathrm{~K})=-242 \mathrm{~kJ} \mathrm{~mol}^{-1} \\
& \rightarrow \mathrm{N}\left({ }^{4} \mathrm{~S}\right)+{ }^{1} \mathrm{HCN} & \Delta H_{r}(298 \mathrm{~K})=-153 \mathrm{~kJ} \mathrm{~mol}^{-1} .
\end{aligned}
$$

To estimate the branching ratio we can use the various calculations performed for the $\mathrm{CH}+\mathrm{N}_{2}$ system (Moskaleva et al. 2000; Berman et al. 2007) which strongly suggest that $\mathrm{CH}+\mathrm{N}_{2}$ is the most favored exit channel. As there is no barrier for only two surfaces, there is an electronic factor equal to $2 / 5$. The simple capture rate constant model based on dispersion only leads to a rate constant close to $(2 / 5) \times 4.0 \times 10^{-10} \times(T / 300)^{-0.17}=$ $1.6 \times 10^{-10} \times(T / 300)^{-0.17} \mathrm{~cm}^{3}$ molecule $\mathrm{s}^{-1}$. This rate constant is higher than those for similar reactions, $\mathrm{N}\left({ }^{2} \mathrm{D}\right)+$ singlet state molecules such as $\mathrm{N}\left({ }^{2} \mathrm{D}\right)+\mathrm{H}_{2} \mathrm{O}$ and $\mathrm{N}\left({ }^{2} \mathrm{D}\right)+\mathrm{NH}_{3}$ reactions which are also likely to occur without a barrier considering their high rate constant values at $300 \mathrm{~K}, 4.0 \times 10^{-11}$ and $5.0 \times$ $10^{-11} \mathrm{~cm}^{3}$ molecule ${ }^{-1} \mathrm{~s}^{-1}$ respectively (Takayanagi et al. 1998; Herron 1999). To evaluate more carefully the $\mathrm{N}\left({ }^{2} \mathrm{D}\right)+\mathrm{HCN}$ rate constant, we performed MRCI+Q/vtz and R-CCSD(T)/vtz calculations for the $\mathrm{N}\left({ }^{2} \mathrm{D}\right)+\mathrm{NH}_{3}$ reaction also showing no barrier for ${ }^{2} \mathrm{~B}_{1}$ and ${ }^{2} \mathrm{~B}_{2}$ surfaces. The difference between the experimental value and the higher capture rate value may be due to several reasons such as a bottleneck in the entrance valley (the interaction potential is attractive mainly around linear attack)

\begin{tabular}{|c|c|c|c|}
\hline Reaction & $k\left(\mathrm{~cm}^{3}\right.$ molecule $\left.^{-1} \mathrm{~s}^{-1}\right)$ & & $g$ \\
\hline $\mathrm{N}\left({ }^{2} \mathrm{D}\right)+\mathrm{HCN} \rightarrow \mathrm{CH}+\mathrm{N}_{2}$ & $5.0 \times 10^{-11}$ & 3 & 0 \\
\hline
\end{tabular}
and/or eventually to a possible relaxation $\left(\mathrm{N}\left({ }^{2} \mathrm{D}\right) \rightarrow \mathrm{N}\left({ }^{4} \mathrm{~S}\right)\right)$. The capture rate constant is a maximum value and therefore, the actual rate constant is likely to be smaller, around (4-6) $\times$ $10^{-11} \mathrm{~cm}^{3}$ molecule ${ }^{-1} \mathrm{~s}^{-1}$ by comparison with $\mathrm{N}\left({ }^{2} \mathrm{D}\right)+\mathrm{H}_{2} \mathrm{O}$ and $\mathrm{N}\left({ }^{2} \mathrm{D}\right)+\mathrm{NH}_{3}$ reactions.

\section{References}

Adriani, A., Dinelli, B. M., López-Puertas, M., et al. 2011, Icarus, 214, 584 Balucani, N., Bergeat, A., Cartechini, L., et al. 2009, J. Chem. Phys. A, 113, 11138

Banaszkiewicz, M., Lara, L. M., Rodrigo, R., López-Moreno, J. J., \& Molina-Cuberos, G. J. 2000, Icarus, 147, 386
Baulch, D., Bowman, C., Cobos, C., et al. 2005, J. Phys. Chem. Ref. Data, 34, 757

Bergeat, A., Moisan, S., Méreau, R., \& Loison, J.-C. 2009, Chem. Phys. Lett., 480,21

Berman, M., Tsuchiya, T., Gregusova, A., Perera, S., \& Bartlett, R. 2007, J. Phys. Chem. A, 111, 6894

BIPM, IEC, IFCC, ISO, IUPAC, IUPAP, \& OIML 2006, Evaluation of measurement data - Supplement 1 to the GUM: Propagation of distributions using a Monte-Carlo method, Tech. rep., BIPM

BIPM, IEC, IFCC, ISO, IUPAC, IUPAP, \& OIML 2008, Evaluation of the measurement data - Guide to the expression of uncertainty in measurement (GUM), Tech. rep., International Organization for Standardization (ISO), Geneva

Bruna, P., Krumbach, V., \& Peyerimhoff, S. 1985, Can. J. Chem., 63, 1594

Carrasco, N., Hébrard, E., Banaszkiewicz, M., Dobrijevic, M., \& Pernot, P. 2007, Icarus, 192, 519

Chestnut, D. 2001, J. Comp. Chem., 22, 1702

Cimas, A., \& Largo, A. 2006, J. Phys. Chem. A, 110, 10912

DePrince III, A., \& Mazziotti, D. 2008, J. Phys. Chem. B, 112, 16158

Dobrijevic, M., Carrasco, N., Hébrard, E., \& Pernot, P. 2008, Planet. Space Sci., 56,1630

Dobrijevic, M., Cavalié, T., Hébrard, E., et al. 2010a, Planet. Space Sci., 58, 1555

Dobrijevic, M., Hébrard, E., Plessis, S., et al. 2010b, Adv. Space Res., 45, 77

Du, B., \& Zhang, W. 2006, Int. J. Quantum Chem., 106, 1827

Dunn, M. R., Freeman, C. G., McEwan, M. J., \& Phillips, L. F. 1971, J. Phys. Chem., 75, 2662

Eden, S., Limão-Vieira, P., Kendall, P., et al. 2003, Eur. Phys. J. D, 26, 201 Feuchtgruber, H., Lellouch, E., de Graauw, T., et al. 1997, Nature, 389, 159

Forst, W. 2003, Unimolecular reactions: a concise introduction (Cambridge University Press)

Frisch, M. J., Trucks, G. W., Schlegel, H. B., et al. 2009, Gaussian 09 Revision A.1, gaussian Inc. Wallingford CT

Geballe, T. R., Kim, S. J., Noll, K. S., \& Griffith, C. A. 2003, ApJ, 583, L39

Georgievskii, Y., \& Klippenstein, S. J. 2005, J. Chem. Phys., 122, 194103

Gurwell, M., \& Muhleman, D. 2000, Icarus, 145, 653

Harding, L. B., Georgievskii, Y., \& Klippenstein, S. J. 2005, J. Phys. Chem. A, 109,4646

Hartogh, P., Lellouch, E., Crovisier, J., et al. 2009, Planet. Space Sci., 57, 1596

Hébrard, E., Dobrijevic, M., Bénilan, Y., \& Raulin, F. 2006, J. Photochem. Photobiol. C: Photochem. Rev., 7, 211

Hébrard, E., Dobrijevic, M., Bénilan, Y., \& Raulin, F. 2007, Plane. Space Sci., 55,1470

Hébrard, E., Dobrijevic, M., Pernot, P., et al. 2009, J. Phys. Chem. A, 113, 11227

Herbst, E., Terzieva, R., \& Talbi, D. 2000, MNRAS, 311, 869

Herron, J. T. 1999, J. Phys. Chem. Ref. Data, 28, 1453

Hindmarsh, A. C. 1983, Scientific Computing, 55

Hörst, S. M., Vuitton, V., \& Yelle, R. V. 2008, J. Geophys. Res. Planet., 113, 10006

Hubin-Franskin, M.-J., Delwiche, J., Giuliani, A., et al. 2002, J. Chem. Phys., 116,9261

Kim, S. J., Geballe, T. R., Noll, K. S., \& Courtin, R. 2005, Icarus, 173, 522

Klippenstein, J., Georgievskii, Y., \& Harding, L. B. 2006, Phys. Chem. Chem. Phys., 8, 1133

Krasnopolsky, V. A. 2009, Icarus, 201, 226

Lara, L. M., Lellouch, E., Lòpez-Moreno, J. J., \& Rodrigo, R. 1996, J. Geophys. Res. Planets, 101, 23261

Larson, C., Ji, Y., Samartzis, P., et al. 2006, J. Chem. Phys., 125, 133302

Lavvas, P. P., Coustenis, A., \& Vardavas, I. M. 2008, Planet. Space Sci., 56, 27

Magee, B. A., Waite, J. H., Mandt, K. E., et al. 2009, Planet. Space Sci., 57, 1895

Marston, G., Nesbitt, F. L., Nava, D. F., Payne, W. A., \& Stief, L. J. 1989a, J. Phys. Chem., 93, 5769

Marston, G., Nesbitt, F. L., \& Stief, L. J. 1989b, J. Chem. Phys., 91, 3483

Moreno, R., Lellouch, E., Hartogh, P., et al. 2010, BAAS, 42, 1088

Moreno, R., Lellouch, E., Lara, L., et al. 2011, A\&A, 536, L12

Moskaleva, L. V., Xia, W. S., \& Lin, M. C. 2000, Chem. Phys. Lett., 331, 269

Nesbitt, F. L., Marston, G., \& Stief, L. J. 1990, J. Phys. Chem., 94, 4946

Nguyen, M. T., Sengupta, D., \& Ha, T. 1996, J. Phys. Chem., 100, 6499

Nizamov, B., \& Dagdigian, P. 2003, J. Phys. Chem. A, 107, 2256

Osamura, Y., \& Petrie, S. 2004, J. Phys. Chem. A, 108, 3615

Ouk, C. M., Zvereva-Loete, N., \& Bussery-Honvault, B. 2011, Chem. Phys. Lett., 515,13

Peng, Z., Cailliez, F., Dobrijevic, M., \& Pernot, P. 2012, Icarus, submitted

Petrie, S. 2001, Icarus, 151, 196

Petrie, S. 2002, J. Phys. Chem. A, 106, 11181

Plessis, S., Carrasco, N., Dobrijevic, M., \& Pernot, P. 2012, Icarus, submitted

Ralchenko, Y., Kramida, A., Reader, J., \& Team, N. A. 2011, NIST Atomic Spectra Database (version 4.1) [Online], available: http://physics.nist. gov/asd 
E. Hébrard et al.: Neutral production of HNC and HCN in Titan's upper atmosphere

Samuelson, R., Nath, N., \& Borysow, A. 1997, Planet. Space Sci., 45, 959

Shemansky, D. E., Stewart, A. I. F., West, R. A., et al. 2005, Science, 308, 978

Sims, I. R., Queffelec, J. L., Travers, D., et al. 1993, Chem. Phys. Lett., 211, 461

Stoecklin, T., \& Clary, D. C. 1992, J. Phys. Chem., 96, 7346

Strobel, D. F., Summers, M. E., \& Zhu, X. 1992, Icarus, 100, 512

Sumathi, R. 1996, J. Mol. Struc., 364, 97

Sumathi, R., \& Nguyen, M. T. 1998, J. Phys. Chem. A, 102, 8013

Takayanagi, T., \& Kurosaki, Y. 1999, J. Mol. Struct. (Theochem), 492, 151

Takayanagi, T., Kurosaki, Y., Misawa, K., et al. 1998, J. Phys. Chem. A, 102, 6251

Takayanagi, T., Kurosaki, Y., Sato, K., et al. 1999, J. Phys. Chem. A, 103, 250

Talbi, D., \& Ellinger, Y. 1996, Chem. Phys. Lett., 263, 385

Teslja, A., Dagdigian, P., Banck, M., \& Eisfeld, W. 2006, J. Phys. Chem. A, 110, 7826

Toublanc, D., Parisot, J. P., Brillet, J., et al. 1995, Icarus., 113, 2

Umemoto, H., Nakae, T., Hashimoto, H., Kongo, K., \& Kawasaki, M. 1998, J. Chem. Phys., 109, 5844
Vaghjiani, G. 1993, J. Chem. Phys., 98, 2123

Vasyunin, A. I., Semenov, D., Henning, T., et al. 2008, ApJ, 672, 629

Vervack, R. J., Sandel, B. R., \& Strobel, D. F. 2004, Icarus, 170, 91

Vinatier, S., Bézard, B., Fouchet, T., et al. 2007, Icarus, 188, 120

Vuitton, V., Yelle, R. V., \& McEwan, M. J. 2007, Icarus, 191, 722

Wakelam, V., Herbst, E., Loison, J.-C., et al. 2012, ApJS, 199, 21

Werner, H.-J., Knowles, P. J., Knizia, G., et al. 2010, MOLPRO, version 2010.1, a package of ab initio programs, http://www. molpro.net

Wilson, E. H., \& Atreya, S. K. 2004, J. Geophys. Res. (Planets), 109, 6002

Yang, D. L., Yu, T., Wang, N. S., \& Lin, M. C. 1992, Chem. Phys., 160

Yelle, R. V., \& Griffith, C. A. 2003, Icarus, 166, 107

Yelle, R., Strobel, D., Lellouch, E., \& Gautier, D. 1997, in Huyghens: Science, payload and mission, ed. A. Wilson (Noordwijk, The Netherlands: ESA Publications Division, ESTEC), ESA SP, 1177, 243

Yung, Y. L., Allen, M., \& Pinto, J. P. 1984, ApJS, 55, 465

Zabarnick, S., Fleming, J. W., \& Lin, M. C. 1991, Chem. Phys., 150, 109

Zhou, J., \& Schlegel, H. B. 2009, J. Phys. Chem. A, 113, 9958 